\title{
Modelling the effect of boundary scavenging on Thorium and Protactinium profiles in the ocean
}

\author{
M. Roy-Barman \\ LSCE/IPSL Laboratoire CNRS/CEA/UVSQ, Domaine du CNRS, Bât 12 - avenue de la Terrasse, 91198 Gif-sur-Yvette \\ Cedex, France
}

Received: 11 June 2009 - Published in Biogeosciences Discuss.: 31 July 2009

Revised: 15 November 2009 - Accepted: 18 November 2009 - Published: 18 December 2009

\begin{abstract}
The "boundary scavenging" box model is a cornerstone of our understanding of the particle-reactive radionuclide fluxes between the open ocean and the ocean margins. However, it does not describe the radionuclide profiles in the water column. Here, I present the transportreaction equations for radionuclides transported vertically by reversible scavenging on settling particles and laterally by horizontal currents between the margin and the open ocean. Analytical solutions of these equations are compared with existing data. In the Pacific Ocean, the model produces "almost" linear ${ }^{230} \mathrm{Th}$ profiles (as observed in the data) despite lateral transport. However, omitting lateral transport biaises the ${ }^{230} \mathrm{Th}$ based particle flux estimates by as much as $50 \%$. ${ }^{231} \mathrm{~Pa}$ profiles are well reproduced in the whole water column of the Pacific Margin and from the surface down to $3000 \mathrm{~m}$ in the Pacific subtropical gyre. Enhanced bottom scavenging or inflow of ${ }^{231} \mathrm{~Pa}$-poor equatorial water may account for the model-data discrepancy below $3000 \mathrm{~m}$. The lithogenic ${ }^{232} \mathrm{Th}$ is modelled using the same transport parameters as ${ }^{230} \mathrm{Th}$ but a different source function. The main source of the ${ }^{232} \mathrm{Th}$ scavenged in the open Pacific is advection from the ocean margin, whereas a net flux of ${ }^{230} \mathrm{Th}$ produced in the open Pacific is advected and scavenged at the margin, illustrating boundary exchange. In the Arctic Ocean, the model reproduces ${ }^{230} \mathrm{Th}$ measured profiles that the uni-dimensional scavenging model or the scavenging-ventilation model failed to explain. Moreover, if lateral transport is ignored, the ${ }^{230} \mathrm{Th}$ based particle settling speed may by underestimated by a factor 4 at the Arctic Ocean margin. The very low scavenging rate in the open Arctic Ocean combined with the enhanced scavenging at the margin accounts for the lack of high ${ }^{231} \mathrm{~Pa} /{ }^{230} \mathrm{Th}$ ratio in arctic sediments.
\end{abstract}

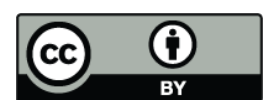

Correspondence to: M. Roy-Barman (matthieu.roy-barman@1sce.ipsl.fr)

\section{Introduction}

${ }^{230} \mathrm{Th}$ and ${ }^{231} \mathrm{~Pa}$ are important oceanic tracers of marine particles and deep water circulations. ${ }^{230} \mathrm{Th}$ and ${ }^{231} \mathrm{~Pa}$ are both produced uniformly in the ocean by radioactive decay of uranium isotopes $\left({ }^{234} \mathrm{U}\right.$ and ${ }^{235} \mathrm{U}$ respectively) and they are both scavenged rapidly on marine particles that transport them towards the sediment on a time scale of $20 \mathrm{y}$ for ${ }^{230} \mathrm{Th}$ and of $200 \mathrm{y}$ for ${ }^{231} \mathrm{~Pa}$. In absence of lateral transport by currents, particulate transport balances in situ production. In this case, the vertical profiles of ${ }^{230} \mathrm{Th}$ and ${ }^{231} \mathrm{~Pa}$ are expected to increase linearly with depth, as predicted by the uni-dimensional ("1-D”) reversible scavenging model (Bacon and Anderson, 1982). Deviations from a linear profile indicate that oceanic currents carry significant amounts of ${ }^{230} \mathrm{Th}$ and ${ }^{231} \mathrm{~Pa}$ away from their production site (Coppola et al., 2006; Roy-Barman et al., 2002; Rutgers van der Loeff and Berger, 1993). The early study of ${ }^{230} \mathrm{Th}$ in the ocean revealed linear increase of dissolved ${ }^{230} \mathrm{Th}$ with depth in agreement with the balance between the in situ production and the reversible scavenging of ${ }^{230} \mathrm{Th}$ on sinking particles (Bacon and Anderson, 1982; Nozaki et al., 1981). Further works have stressed that a significant fraction of dissolved ${ }^{231} \mathrm{~Pa}$ and at least some dissolved ${ }^{230} \mathrm{Th}$ could be exported from area of low particle flux to area with high particle flux where ${ }^{230} \mathrm{Th}$ and ${ }^{231} \mathrm{~Pa}$ are efficiently scavenged to the sediment (Anderson et al., 1983). This process is called "boundary scavenging" because ocean boundaries/margins are generally places with high particle concentration and sedimentation rates (particle flux effect) and where the particulate matter chemistry is such that it has a higher affinity for Pa compared to the open ocean (particle chemistry effect). The concept of boundary scavenging was first applied to horizontal transport of ${ }^{210} \mathrm{~Pb}$ toward lateral ocean boundaries (Bacon, 1977; Spencer et al., 1981). The effect of the lateral transport on particulate flux of ${ }^{230} \mathrm{Th}$ and ${ }^{231} \mathrm{~Pa}$ was quantified with box modelling, hereafter referred as boundary scavenging

Published by Copernicus Publications on behalf of the European Geosciences Union. 
margin

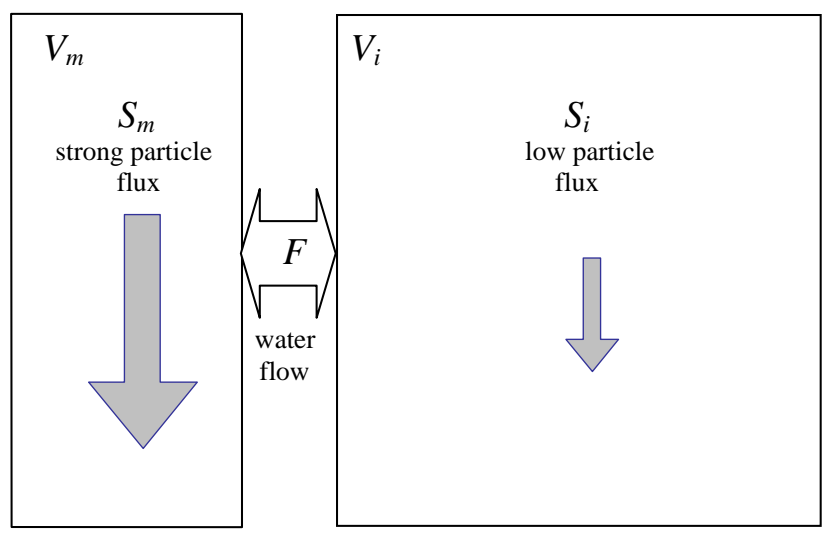

Fig. 1. Principle of the boundary scavenging profile model.

box model (Anderson et al., 1983; Bacon, 1988; Bacon et al., 1985). More than 25 years later, this model is still the cornerstone of our understanding of the distribution of the particle reactive element fluxes between the margins and the open ocean. In this box model, only the depth-averaged concentrations of $\mathrm{Pa}$ and $\mathrm{Th}$ are considered, but the water column profiles are not modelled. Nevertheless, it was noted that the greater sensitivity of ${ }^{231} \mathrm{~Pa}$ to boundary scavenging compared to ${ }^{230} \mathrm{Th}$ could account for its constant concentration in the deep water as opposed to the linear increase of ${ }^{230} \mathrm{Th}$ (Nozaki and Nakanishi, 1985). As a consequence, despite the potential influence of boundary scavenging in most oceanic regions, the 1-D reversible scavenging model is widely used to discuss ${ }^{230}$ Th water column data and determine particle settling velocities including in ocean margins, as long as there is no obvious evidence of ventilation or upwelling. However, a recent study of the particle dynamics on the Kerguelen plateau stressed on the importance of taking into account horizontal advection of the open ocean water to evaluate the particles flux with the dissolved and particulate ${ }^{230} \mathrm{Th}$ profiles (Venchiarutti et al., 2008).

Here, I model the water column profiles of ${ }^{230} \mathrm{Th},{ }^{232} \mathrm{Th}$ and ${ }^{231} \mathrm{~Pa}$ corresponding to the 2 box ocean (ocean margin and ocean interior) proposed by (Bacon, 1988) or more generally when 2 areas with distinct scavenging conditions exchange water. I use the simple approach of (Rutgers van der Loeff and Berger, 1993) and (Venchiarutti et al., 2008) to obtain analytical solutions of the transport equations. Then, I compare the results with some existing data to discuss the shape of the Th-Pa profiles and the evaluation of the particle flux with ${ }^{230} \mathrm{Th}$ profiles.

\section{The boundary scavenging profile model}

\subsection{Boxes and water transport}

The ocean is divided in 2 boxes: the ocean margin and the ocean interior (Fig. 1). The volumes of the margin and of the ocean interior are $V_{m}$ and $V_{i}\left(\mathrm{~m}^{3}\right)$. These 2 boxes exchange a total flux of water $F\left(\mathrm{~m}^{3} / \mathrm{s}\right)$. For simplicity, I assume that the water flows horizontally between the boxes (this is true if isopycnal surfaces are essentially horizontal) and that this flux is homogeneously distributed throughout the water column (a similar hypothesis is done by Rutgers van der Loeff and Berger, 1993). The vertical eddy diffusion is neglected in the surface mixed layer (see Sect. 2.4) and in the deep waters (see Sect. 3.1.1). Neglecting vertical mixing within each box implies that ventilation of deep layers by lateral exchange with Polar Regions is also neglected (this point will be justified for the North Pacific Ocean in Sect. 3.1.1 and the Arctic Ocean in Sect. 3.2.1). It follows that at any depth the residence time of the water is $\tau_{m}=V_{m} / F$ in the margin and $\tau_{i}=V_{i} / F$ in the ocean interior. Keeping constant $\tau_{m}$ and $F$ values with depth implicitly implies the crude approximation that the ocean margin has a flat bottom bathymetry (Fig. 1) rather than a deepening slope. It must be noted that each box is assumed to be well mixed horizontally so that concentration gradients exist just between the boxes, not within boxes. It implies that the nuclide distribution should be represented by an average profile rather than by a single profile. As discussed in Sect. 3.1.3, using an "extreme" profiles (e.g. a profile sampled in the centre of the gyre) rather than an average profile over the box (average profile over the gyre if available) will lead to somewhat different estimates of the mixing time that reflect the strong isolation of the gyre centre from the margin compared to the whole gyre.

\subsection{Particle flux}

Particles are assumed to be produced at the sea surface $(z=0)$. Then, particles settle at constant velocity: $S_{m}$ for the margin and $S_{i}$ for the ocean interior. These settling velocities represent the mean settling velocity of small particles defined operationally as the particles collected on filters with porosity ranging from 0.2 to $1 \mu \mathrm{m}$. This average settling velocity of the fine particle integrates multiple processes including aggregation of small particles on large rapidly sinking particles and desegregation that are not explicitly represented in the model. The particle concentration is also not explicitly considered here. The particle concentration is embedded in the dissolved-particulate partition coefficient $K$ introduced in the next section.

I also assume that the constant particle flux is not perturbed by lateral transport of particles from one oceanic reservoir to the other. This is justified because, for transport at the ocean basin scale, marine particles settle through the entire water column fast enough that they do not have time to be 
advected far from their region of origin before they reach the seafloor (Henderson et al., 1999; Siddall et al., 2005). It is also consistent with the idea that particle dynamics in the water column is strongly driven by surface parameters such as biological productivity in the local surface water (high settling speed of particles in productive area, low settling speed of particles in oligotrophic areas).

The treatment of the particle transport is simplistic compared to the complexity of the real particle dynamics. The aim is to use the same particle dynamics as the 1-D reversible scavenging model (Bacon and Anderson, 1982; Nozaki et al., 1981) in order to restrict the investigation to the effect of lateral transport on radionuclide distribution.

\subsection{Tracer transport}

In each box, ${ }^{230} \mathrm{Th}$ (as well as ${ }^{231} \mathrm{~Pa}$ ) is produced by in situ decay of $\mathrm{U}$ at a constant rate $P$, it is transported toward the sea floor by reversible scavenging on sinking particles and it is transported horizontally by the water flow. Considering the long half-life of ${ }^{230} \mathrm{Th}(75000 \mathrm{y})$ and ${ }^{231} \mathrm{~Pa}(32500 \mathrm{y})$, the radioactive decay of these isotopes is neglected. Dissolved and particulate concentrations are noted $C_{d}^{m}$ and $C_{p}^{m}$ for the margin and $C_{d}^{i}$ and $C_{p}^{i}$ for the ocean interior.

The total quantity of tracer (dissolved + particulate) is transported horizontally from one reservoir to the other (Siddall et al., 2005). The conservation equation of total ${ }^{230} \mathrm{Th}$ (or ${ }^{231} \mathrm{~Pa}$ ) is given by:

for the ocean margin:

$$
\begin{aligned}
\frac{d\left(C_{d}^{m}+C_{p}^{m}\right)}{d t}= & -S_{m} \frac{d C_{p}^{m}}{d z}+P \\
& +\frac{F}{V_{m}}\left[\left(C_{d}^{i}+C_{p}^{i}\right)-\left(C_{d}^{m}+C_{p}^{m}\right)\right]
\end{aligned}
$$

for the inner ocean:

$$
\begin{aligned}
\frac{d\left(C_{d}^{i}+C_{p}^{i}\right)}{d t}= & -S_{i} \frac{d C_{p}^{i}}{d z}+P \\
& +\frac{F}{V_{i}}\left[\left(C_{d}^{m}+C_{p}^{m}\right)-\left(C_{d}^{i}+C_{p}^{i}\right)\right]
\end{aligned}
$$

In the right member of these equations, the first term represents the vertical particulate transport, the second term represents the in situ production and the third term corresponds to the lateral transport. To solve these equations, the relation between $C_{p}$ and $C_{d}$ need to be specified. The dissolved and particulate pools exchange material through adsorption and desorption. If these processes are fast enough, it can be assumed that there is a chemical equilibrium between the dissolved and the particulate pool (Bacon and Anderson, 1982; Nozaki et al., 1981; Roy-Barman et al., 1996):

$C_{p}^{m}=K_{m} C_{d}^{m}$

$C_{p}^{i}=K_{i} C_{d}^{i}$

$\mathrm{K}$ represents the apparent partition coefficient of Th between the dissolved and the particulate phase with $C_{p}$ expressed as $g$ of Th per litre of filtered seawater. These relations express a fast reversible equilibrium between dissolved and particulate thorium. This is the assumption used in the 1-D model and the scavenging-mixing model to represent the dissolved-particulate relationship (Bacon and Anderson, 1982; Coppola et al., 2006; Moran et al., 2002; Nozaki et al., 1981; Roy-Barman et al., 1996, 2002; Rutgers van der Loeff and Berger, 1993). The determination of the partition coefficient of $\mathrm{Pa}$ and $\mathrm{Th}$ between the various particle types is still a matter of debate (Chase et al., 2002; Santschi et al. 2006; Roy-Barman et al., 2005, 2009). This is why I did not try to represent particles of different chemical composition with specific $K$ but I rather used a bulk partition coefficient. In the following, $\mathrm{K}$ is assumed to be constant with depth for both Th and Pa, as also assumed in the 1-D model and the scavenging-mixing model. This may be questionable as, for example, degradation and dissolution of biogenic particles causes the abundance and composition of particles to vary with depth. A significant dissolution of Th bearing phases would produce a non-linear profile that is not consistent with observations (Roy-Barman et al., 1996). Pa is preferentially scavenged by biogenic silica that is known to experience dissolution through the water column (Scholten et al., 2008). However, the accelerated increase of dissolved ${ }^{231} \mathrm{~Pa}$ with depth that could be expected (based on the analysis of ${ }^{230}$ Th distribution by Roy-Barman et al., 1996) does not appear clearly in the data (Nozaki and Nakanishi, 1985; Bacon et al., 1989).

\subsection{Solving the equilibrium model}

Assuming that each reservoir is at steady state and introducing the reversible equilibrium between dissolved and particulate thoriumin (Eq. 1a and b), it follows that:

$$
-S_{m} K_{m} \frac{d C_{d}^{m}}{d z}+P+\frac{F}{V_{m}}\left[\left(1+K_{i}\right) C_{d}^{i}-\left(1+K_{m}\right) C_{d}^{m}\right]=0
$$

for the inner ocean:

$$
-S_{i} K_{i} \frac{d C_{d}^{i}}{d z}+P+\frac{F}{V_{i}}\left[\left(1+K_{m}\right) C_{d}^{m}-\left(1+K_{i}\right) C_{d}^{i}\right]=0
$$

First I consider only the in situ produced ${ }^{230} \mathrm{Th}$ (also called ${ }^{230} \mathrm{Th}_{x s}$ ). If the effect of the mixed layer is neglected (RoyBarman et al., 1996), the amount ${ }^{230} \mathrm{Th}$ produced at $z=0$ in an infinitely thin layer tends towards 0 , so that in this layer, marine particles have not accumulated ${ }^{230} \mathrm{Th}$. It follows 2 boundary conditions: $C_{p}^{m}=0$ and $C_{p}^{i}=0$. It implies that $C_{d}^{m}=C_{p}^{m} / K_{m}=0$ and $C_{d}^{i}=C_{p}^{i} / K_{i}=0$.

Under these conditions, the solutions of Eq. (3a) and ( $3 b)$ are (see Appendix A):

$$
\begin{aligned}
& C_{d}^{i}=\frac{\sigma_{\infty}}{\left(1+K_{i}\right)} \times z+\left(\frac{P}{S_{i} K_{i}}-\frac{\sigma_{\infty}}{\left(1+K_{i}\right)}\right) \times z_{0} \times\left(1-e^{-\left(\frac{z}{z_{0}}\right)}\right) \\
& C_{d}^{m}=\frac{\sigma_{\infty}}{\left(1+K_{m}\right)} \times z+\left(\frac{P}{S_{m} K_{m}}-\frac{\sigma_{\infty}}{\left(1+K_{m}\right)}\right) \times z_{0} \times\left(1-e^{-\left(\frac{z}{z_{0}}\right)}\right)
\end{aligned}
$$


with

$z_{0}=\left(\frac{F}{V_{i}} \frac{\left(1+K_{i}\right)}{S_{i} K_{i}}+\frac{F}{V_{m}} \frac{\left(1+K_{m}\right)}{S_{m} K_{m}}\right)^{-1}$

and

$\sigma_{\infty}=\frac{P\left(V_{m}+V_{i}\right)}{\frac{S_{m} K_{m} V_{m}}{\left(1+K_{m}\right)}+\frac{S_{i} V_{i} K_{i}}{\left(1+K_{i}\right)}}$

$z_{0}$ is the depth below which lateral mixing becomes significant compared to particulate transport. $\sigma_{\infty}$ represents the slope of the total (dissolved + particulate) ${ }^{230}$ Th concentration depth profiles at great depth $\left(z \gg z_{0}\right)$ in the margin and the inner ocean. Equation (4a) and (4b) are converted to the total quantity of ${ }^{230} \mathrm{Th}$ as follow:

$C_{t}^{i}=\sigma_{\infty} \times z+\left(\sigma_{i}-\sigma_{\infty}\right) \times z_{0} \times\left(1-e^{-\left(\frac{z}{z_{0}}\right)}\right)$

$C_{t}^{m}=\sigma_{\infty} \times z+\left(\sigma_{m}-\sigma_{\infty}\right) \times z_{0} \times\left(1-e^{-\left(\frac{z}{z_{0}}\right)}\right)$

where $\sigma_{m}=\left(1+K_{m}\right) \times P /\left(S_{m} K_{m}\right)$ and $\sigma_{i}=\left(1+K_{i}\right) \times P /\left(S_{i} K_{i}\right)$ represent the slopes of the total (dissolved + particulate) ${ }^{230} \mathrm{Th}$ concentration depth profiles that would be observed in the margin and the inner ocean if there was no lateral mixing $(F=0)$. In the following, these equations will be referred as "the boundary scavenging profile model".

\section{Discussion}

The model will be compared with existing data from the Pacific Ocean and the Arctic Ocean. The Pacific Ocean is the largest ocean so that margin-interior interactions should occur on a relatively long time scale. The Arctic Ocean is smaller than the Pacific. It is the ocean with the largest proportion of shelves and marginal seas whereas the inner ocean is permanently covered by sea-ice, producing a very strong biogeochemical contrast between the margin and the inner ocean. I do not try to compare directly the model with Atlantic Ocean data because the strong ventilation of the deep waters strongly influences the shape of the $\mathrm{Pa}$ and Th profiles. However, implications of the model for the Atlantic Ocean will be discussed.

\subsection{North Pacific Ocean}

\subsection{1 $\quad 230$ Th}

I focus on the North Pacific Ocean because it covers most available data in the Pacific Ocean. The margin-inner ocean limit is set at the $4000 \mathrm{~m}$ isobath. The water residence times used by (Bacon, 1988) were: $\tau_{i}=460 \mathrm{y}, \tau_{m}=140 \mathrm{y}$. The dense waters formed in the North Pacific flow as intermediate water above $1000 \mathrm{~m}$, while denser waters of the North Pacific are dominated by the inflow from the South Pacific (Reid,
1997). In the Central North Pacific, were ${ }^{230}$ Th scavenging is particularly slow (Roy-Barman et al., 1996), CFC-ages of recently ventilated waters $(\sim 0-1000 \mathrm{~m}$ in the thermocline $)$ are approximately 4 times larger than the ${ }^{230} \mathrm{Th}$ scavenging residence time calculated at the same depth, indicating that ${ }^{230} \mathrm{Th}$ transport is dominated by the reversible scavenging rather than by water ventilation (Fine et al., 2001; Boyle et al., 2005). In addition, it must be kept in mind that CFCages may be strongly biased toward young ages due to water mass mixing. Therefore, it is likely that ${ }^{230} \mathrm{Th}$ profiles are not strongly affected by the thermocline ventilation in the North Pacific Ocean. The effect of ventilation is certainly stronger for ${ }^{231} \mathrm{~Pa}$ that has a longer scavenging residence time although it is not possible to quantify it clearly.

A profile obtained in the NW Pacific Ocean (AN5: $40^{\circ} 00^{\prime} \mathrm{N}, 145^{\circ} 28^{\prime} \mathrm{E}$ ) is used as reference for the Pacific Ocean margin (Nozaki and Yang, 1987). It was preferred to discrete $\mathrm{Pa}$ and Th data collected less than 50 miles off the slope of the Shikoku Basin because they form a very scattered profile (possibly due to local effects) that corresponds on average to the AN5 profile (Nozaki and Yang, 1987). The inner ocean is represented by the HOT station $\left(22^{\circ} 45^{\prime} \mathrm{N}\right.$, $158^{\circ} \mathrm{W}, \sim 100 \mathrm{~km}$ north of Oahu) in the Central North Pacific Ocean (Roy-Barman et al., 1996). Knowing the concentration profiles and $K$ values from field data, the settling speeds are adjusted to obtain a good agreement with the reference profiles (Table 1, Fig. 2).

The modelled profiles are close to, but not exactly, strait lines (Fig. 2a). At the ocean margin, where scavenging is intense, the deep ${ }^{230} \mathrm{Th}$ concentration is slightly higher than what it would be if no lateral mixing occurred. Conversely, in the inner ocean, the modelled profile exhibit slightly lower concentrations than if no advection occurred. This is because some ${ }^{230} \mathrm{Th}$ is transported from the low particle flux region to the high particle flux region ("particle flux effect").

Above $\sim 1500 \mathrm{~m}$, the boundary scavenging profiles are almost identical to the 1-D scavenging profiles. Indeed, if $z \gg z_{0}$ (Appendix B, Eq. B6a and b)

$$
\begin{aligned}
& C_{d}^{i} \approx \frac{P}{S_{i} K_{i}} \times z \\
& C_{d}^{m} \approx \frac{P}{S_{m} K_{m}} \times z
\end{aligned}
$$

Close to the surface or/and if the water residence time is very long in the inner ocean and in the margin, the effect of lateral transport is negligible and the profiles are identical to those expected without advection. As a consequence, the settling speed of marine particles must be determined with ${ }^{230} \mathrm{Th}$ data collected in the upper part of the water column because they are less likely to be affected by boundary scavenging.

At $z=0$, the boundary condition implies that the ${ }^{230} \mathrm{Th}_{d}$ concentration is equal to zero (no mixed layer). It introduces a small discrepancy with the data. The ${ }^{230} \mathrm{Th}$ concentration over the mixed layer of depth $\mathrm{h}$ is constant and equal to the 
Table 1. Parameters of the boundary scavenging profile model.

\begin{tabular}{|c|c|c|c|c|c|c|}
\hline & \multicolumn{2}{|c|}{$\begin{array}{c}\text { Pacific } 1 \\
\text { (slow mixing) }\end{array}$} & \multicolumn{2}{|c|}{$\begin{array}{c}\text { Pacific } 2 \\
\text { (fast mixing) }\end{array}$} & \multicolumn{2}{|c|}{ Arctic 1} \\
\hline & $\begin{array}{l}\text { inner } \\
\text { ocean }\end{array}$ & $\begin{array}{l}\text { ocean } \\
\text { margin }\end{array}$ & $\begin{array}{l}\text { inner } \\
\text { ocean }\end{array}$ & $\begin{array}{l}\text { ocean } \\
\text { margin }\end{array}$ & $\begin{array}{l}\text { inner } \\
\text { ocean }\end{array}$ & $\begin{array}{l}\text { ocean } \\
\text { margin }\end{array}$ \\
\hline \multicolumn{7}{|l|}{ Circulation } \\
\hline$V\left(\mathrm{~m}^{3}\right)^{\mathrm{a}}$ & $1.64 \times 10^{17}$ & $5 \times 10^{16}$ & $1.64 \times 10^{17}$ & $5 \times 10^{16}$ & $6.5 \times 10^{15}$ & $1.5 \times 10^{15}$ \\
\hline$F\left(\mathrm{~m}^{3} / \mathrm{y}\right)^{\mathrm{b}}$ & $3.57 \times 10^{14}$ & $3.57 \times 10^{14}$ & $1.1 \times 10^{15}$ & $1.1 \times 10^{15}$ & $1.3 \times 10^{14}$ & $1.3 \times 10^{14}$ \\
\hline $\begin{array}{l}\tau(y) \\
\text { particles }\end{array}$ & 460 & 140 & 150 & 45.8 & 50 & 11.5 \\
\hline $\begin{array}{l}S(\mathrm{~m} / \mathrm{y})^{\mathrm{c}} \\
\text { Thorium }\end{array}$ & 370 & 500 & 330 & 700 & 150 & 1500 \\
\hline$P_{\mathrm{Th}}\left(\mathrm{fg} / \mathrm{m}^{3} / \mathrm{y}\right)^{\mathrm{d}}$ & 540 & 540 & 540 & 540 & 540 & 540 \\
\hline$K_{\mathrm{Th}}^{\mathrm{e}}$ & 0.15 & 0.3 & 0.15 & 0.3 & 0.06 & 0.30 \\
\hline$z_{0 \mathrm{Th}}(\mathrm{km})^{\mathrm{f}}$ & 9.3 & 9.3 & 3.2 & 3.2 & 0.38 & 0.38 \\
\hline $\begin{array}{l}\text { Particulate }{ }^{230} \mathrm{Th} \text { flux/ } \\
\text { overlying production } \\
(\text { depth })^{\mathrm{f}}\end{array}$ & $\begin{array}{l}95 \% \\
(4000 \mathrm{~m})\end{array}$ & $\begin{array}{l}115 \% \\
(4000 \mathrm{~m})\end{array}$ & $\begin{array}{l}85 \% \\
(4000 \mathrm{~m})\end{array}$ & $\begin{array}{l}148 \% \\
(4000 \mathrm{~m})\end{array}$ & $\begin{array}{l}29 \% \\
(2000 \mathrm{~m})\end{array}$ & $\begin{array}{l}409 \% \\
(2000 \mathrm{~m})\end{array}$ \\
\hline \multicolumn{7}{|l|}{ Protactinium } \\
\hline$P_{\mathrm{Pa}}\left(\mathrm{fg} / \mathrm{m}^{3} / \mathrm{y}\right)^{\mathrm{d}}$ & 25 & 25 & 25 & 25 & 25 & 25 \\
\hline$K_{\mathrm{Pa}}^{\mathrm{e}}$ & 0.015 & 0.15 & 0.015 & 0.15 & 0.006 & 0.1 \\
\hline$z_{0 \mathrm{~Pa}}(\mathrm{~km})^{\mathrm{f}}$ & 2.0 & 2.0 & 0.6 & 0.6 & 0.043 & 0.043 \\
\hline $\begin{array}{l}\text { Particulate }{ }^{231} \mathrm{~Pa} \text { flux at } \\
\text { depth/overlying } \\
\text { production }{ }^{\mathrm{f}}\end{array}$ & $\begin{array}{l}59 \% \\
(4000 \mathrm{~m})\end{array}$ & $\begin{array}{l}235 \% \\
(4000 \mathrm{~m})\end{array}$ & $\begin{array}{l}25 \% \\
(4000 \mathrm{~m})\end{array}$ & $\begin{array}{l}316 \% \\
(4000 \mathrm{~m})\end{array}$ & $\begin{array}{l}6 \% \\
(2000 \mathrm{~m})\end{array}$ & $\begin{array}{l}509 \% \\
(2000 \mathrm{~m})\end{array}$ \\
\hline $\begin{aligned} F & =(\mathrm{Th} / \mathrm{Pa})_{\mathrm{p}} /(\mathrm{Th} / \mathrm{Pa})_{\mathrm{d}} \\
& =\left(\mathrm{K}^{\mathrm{Th}} / \mathrm{K}^{\mathrm{Pa}}\right)^{\mathrm{f}}\end{aligned}$ & 10 & 2 & 10 & 2 & 10 & 3 \\
\hline$(\mathrm{Pa} / \mathrm{Th})_{\mathrm{p}} /\left(P_{\mathrm{Pa}} / P_{\mathrm{Th}}\right)^{\mathrm{f}}$ & $\begin{array}{l}0.62 \\
(4000 \mathrm{~m})\end{array}$ & $\begin{array}{l}2.0 \\
(4000 \mathrm{~m})\end{array}$ & $\begin{array}{l}0.40 \\
(4000 \mathrm{~m})\end{array}$ & $\begin{array}{l}2.1 \\
(4000 \mathrm{~m})\end{array}$ & $\begin{array}{l}0.2 \\
(2000 \mathrm{~m})\end{array}$ & $\begin{array}{l}1.2 \\
(2000 \mathrm{~m})\end{array}$ \\
\hline
\end{tabular}

a Pacific data from Bacon (1988). Arctic data from Jakobsson (2002).

b Pacific data from Bacon (1988); Matsumoto (2007); Owens and Warren (2001). Arctic data from Carmack et al. (1995).

c values derived in this paper by fitting the modelled ${ }^{230} \mathrm{Th}$ profiles to measured ${ }^{230} \mathrm{Th}$ profiles: Pacific profiles from Roy-Barman et al. (1996); Nozaki and Yang (1987); Arctic profiles: Bacon et al. (1989); Cochran et al. (1995); Edmonds et al. (1998).

d Anderson et al. (1983).

e Pacific data from Anderson et al. (1983); Nozaki and Nakanishi (1985); Nozaki et al. (1987, 1995); Roy-Barman et al. (1996). Arctic data from Bacon et al. (1989); Cochran et al. (1995); Moran et al. (2005); Scholten et al. (1995).

$\mathrm{f}$ values deduced from the other parameters.

concentration expected at the depth $\mathrm{h}$ with the 1-D model if there was no vertical mixing (Roy-Barman et al. 1996). Hence the effect of the mixed layer on the real profile will be limited to the very surface sample(s) and it can be neglected for the purpose of this article where the discussion concerns mostly the deep profile.

At $4000 \mathrm{~m}$, the ${ }^{230} \mathrm{Th}$ particulate flux $\left(S \times C_{p}\right)$ represents $115 \%$ of the in situ production in the overlying water column at the margin and $95 \%$ of the in situ production in the overlying water column in the inner ocean. Thus, the contrast between the margin and the inner ocean is relatively weak compared to the estimates based on a GCM (Henderson et al., 1999). If lateral mixing is ignored, the 1-D reversible model overestimates the settling speed of particles by $\sim 5 \%$ in the inner ocean and underestimated it by $\sim 16 \%$ in the margin. In this particular case, the difference between the advectionmixing model and the 1-D model are relatively small because the water residence time in each reservoir is long compared to the scavenging residence time (Table 1).

However, Bacon (1988) suggested that the relatively long water residence time that he estimated with his box model and data available at the time could be overestimated by a factor 2 to 3 due to the paucity of $\mathrm{Pa}$ and Th water column data. Therefore, the water residence time is re-evaluated using recent data independently of thorium data and boundary scavenging models. 


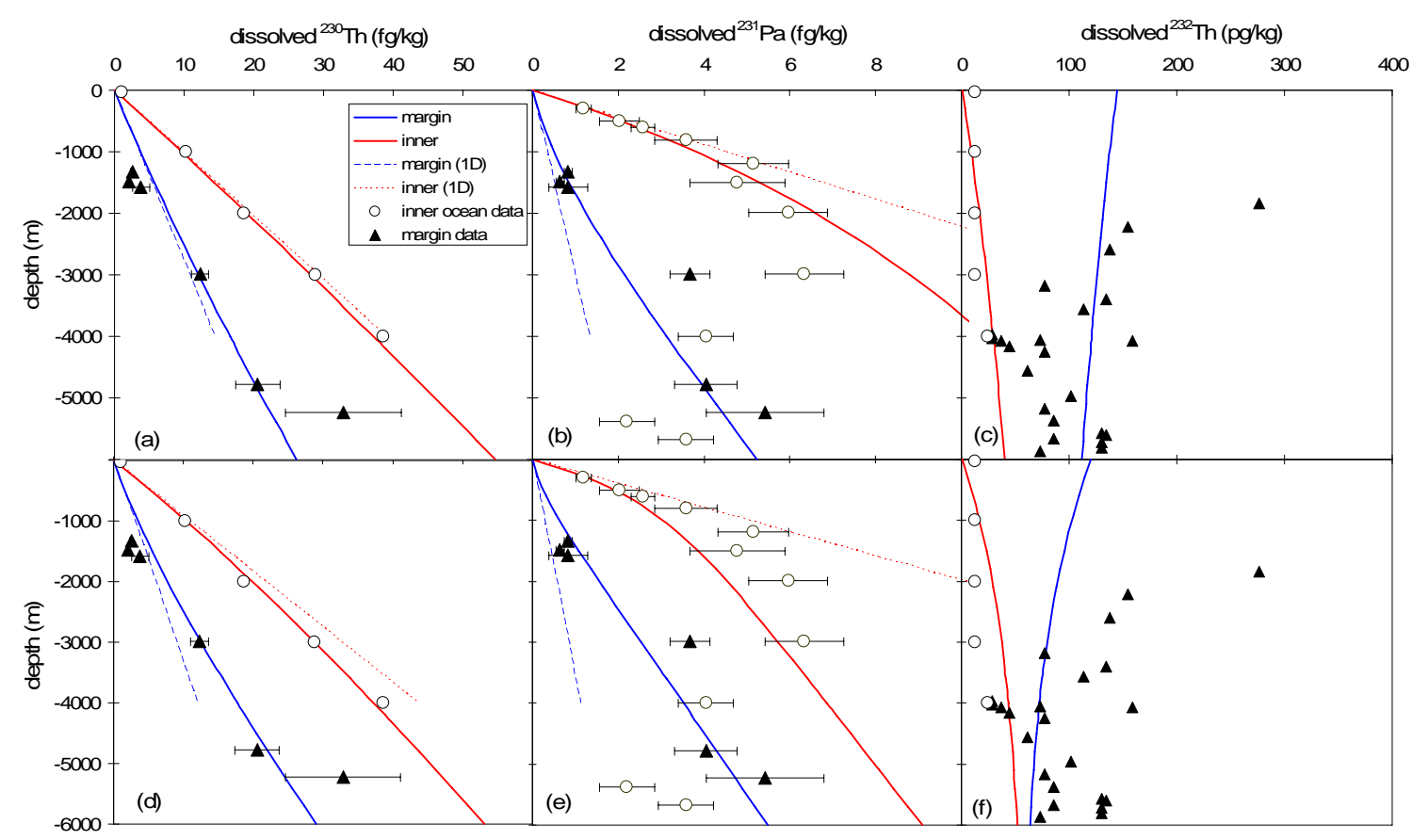

Fig. 2. Modelled profiles and comparison with data for the North Pacific Ocean. (a) to (c): Pacific 1 simulation (slow mixing). (d) to (f): Pacific 2 simulation (fast mixing). See Table 1 for model parameters. "1-D" curves are obtained for the ocean margin and the inner ocean by setting $F=0$ and keeping all the other parameters identical.

A recent synthesis of the $\Delta^{14} \mathrm{C}$ collected during the WOCE program suggests that the mixing time of the deep water between the ocean margin and inner North Pacific is of the order of 100-200 y (Matsumoto, 2007). This mixing time is different from the more familiar absolute age and ventilation age that is of the order of $1000 \mathrm{y}$ (see Matsumoto, 2007, for discussion).

Isopycnal diffusion contribution to margin-open ocean mixing can be evaluated as follows: for a length scale $\Delta x=5000 \mathrm{~km}$ (the distance between the centre of the inner ocean and the margin), the horizontal eddy diffusion coefficient $K_{H}$ is of the order of $2-6 \times 10^{7} \mathrm{~cm}^{2} / \mathrm{s}$ in the deep ocean (Ledwell et al., 1998, Sarmiento et al., 1982), the time scale $\Delta t$ necessary to achieve diffusion is

$\Delta t=\frac{(\Delta x)^{2}}{2 \times K_{H}}$

The above $K_{H}$ values are on the high end of those used in Ocean General Circulation Models to parametrize horizontal eddy diffusion. This is because natural or artificial tracer dispersion integrates also the effect of the large scale circulation. With the above values, we obtain $\Delta t=70-200 \mathrm{y}$ which is in the same range as the ${ }^{14} \mathrm{C}$ estimates. Based on the ${ }^{14} \mathrm{C}$ and the isopycnal diffusion estimates, I choose a residence time of $150 \mathrm{y}$ for the inner deep North Pacific. With a 3.2 to 1 ratio between the inner ocean and the margin (Bacon, 1988), the water residence time in the margin is of the order of $50 \mathrm{y}$. This residence time is consistent with the strong cur- rents $\left(\sim 24 \times 10^{6} \mathrm{~m}^{3} / \mathrm{s}\right.$ below $\left.2000 \mathrm{~m}\right)$ flowing along the Japan slope (Owens and Warren, 2001).

Using these new residence times, it is necessary to increase the $S_{m}$ and to decrease $S_{i}$ to maintain the same concentration gradient with a more vigorous horizontal mixing. Therefore, the deviation between the 1-D and the boundary scavenging profile model increases. At $4000 \mathrm{~m}$ the ${ }^{230} \mathrm{Th}$ particulate flux $\left(S \times C_{p}\right)$ represents $148 \%$ of the in situ production in the overlying water column at the margin and $86 \%$ of the in situ production in the overlying water column in the inner ocean. The scavenging contrast between the margin and the inner ocean become closer to the estimates based on a GCM (Henderson et al., 1999). If lateral mixing is ignored so that the 1-D scavenging model is used to determine the settling speed of particles, the settling speed of particles will be overestimated by $\sim 14 \%$ in the inner ocean and underestimated by $\sim 30 \%(48 \% / 148 \%)$ at the margin.

Finally, it must be noted that vertical (diapicnal) eddy diffusion in the deep ocean cannot account for the curvature of the profile. Using a typical vertical eddy diffusion coefficient in the deep ocean $\mathrm{K}_{z}=1 \mathrm{~cm}^{2} / \mathrm{s}$ (Munk, 1966; Thorpe, 2004) for the whole water column and assuming no diffusion of ${ }^{230} \mathrm{Th}$ from the sediment, it appears that the curvature of the profile due to the vertical eddy diffusivity is restricted within $\sim 100 \mathrm{~m}$ above the seafloor (Roy-Barman et al., 1996). For ${ }^{231} \mathrm{~Pa}$ that will be presented in the next section and that is 10 times les particle reactive than ${ }^{230} \mathrm{Th}$, the curvature of the profile due to the vertical eddy diffusivity is restricted within 
$\sim 500 \mathrm{~m}$ above the seafloor. Higher, $\mathrm{K}_{z}$ value $\left(>1 \mathrm{~cm}^{2} / \mathrm{s}\right)$ occurs in the deep ocean but they are restricted very close to the bottom topography (Ledwell et al., 2000), limiting its effect on the Th or Pa profile to the seafloor vicinity. In addition, it must be noted that isopycnal diffusion along slopping isopycnal surfaces probably accounts for most of the vertical eddy diffusivity in the deep ocean (Sarmiento and Rooth, 1980).

\subsection{2 $\quad{ }^{231} \mathbf{P a}$}

I now apply the boundary scavenging profile model to ${ }^{231} \mathrm{~Pa}$. The water residence time, the settling speed of particles and the boundary conditions remain unchanged compared to simulation (1), the only changes concern $K_{i}$ and $K_{m}$ due to the different chemical behaviour of $\mathrm{Pa}$ and Th. According to literature data (Table 1 ), $K_{i}^{P a} \approx K_{i}^{T h} / 10$ in the inner ocean and $K_{m}^{P a} \approx K_{m}^{T h} / 2$ in the ocean margin (Anderson et al., 1983; Nozaki and Nakanishi, 1985; Nozaki et al., 1987, 1995). The main features of the modelled ${ }^{230} \mathrm{Th}$ profiles also occur for the modelled ${ }^{231} \mathrm{~Pa}$ profiles:

- in the deep ocean, the modelled ${ }^{231} \mathrm{~Pa}$ concentration at the margin is higher and the modelled ${ }^{231} \mathrm{~Pa}$ concentration in the inner ocean is lower than if no lateral mixing occurred $(F=0)$.

- very close to the surface, the advection-scavenging profiles are almost identical to the 1-D scavenging profiles. It occurs only above $\sim 300 \mathrm{~m}$ (compared to $1500 \mathrm{~m}$ for ${ }^{230} \mathrm{Th}$ ) because ${ }^{231} \mathrm{~Pa}$ much more sensitive to lateral mixing than ${ }^{230} \mathrm{Th}$.

At great depth (below $z_{0}$ ), the "margin" and "inner ocean" ${ }^{231} \mathrm{~Pa}$ modelled profiles tend to be parallel. $z_{0}$ is the depth where the 2 profiles start to be parallel due to horizontal mixing of ${ }^{231} \mathrm{~Pa}$. The concentrations remain different because above $z_{0}$ an excess of ${ }^{231} \mathrm{~Pa}$ has built up in the open ocean due to a lower scavenging rate. This excess is transported at greater depth by reversible scavenging on sinking particles. Strictly speaking, it is the slopes of the total concentration profiles that tend toward the same value (Appendix B, Eq. B8a and b).

The difference of concentration between the 2 profiles is equal to $2.5 \mathrm{fg} / 1$ (we neglect particulate $\mathrm{Pa}$ that represents a small fraction of the total). This concentration difference is the result of ${ }^{231} \mathrm{~Pa}$ ingrowth when a ${ }^{231} \mathrm{~Pa}$-depleted water mass leaves the margin (where scavenging is more intense), and stays in the inner ocean (where the scavenging rate is much lower). Dividing this concentration difference by the production rate of ${ }^{231} \mathrm{~Pa}(0.025 \mathrm{fg} / \mathrm{l} / \mathrm{y})$ yields a time difference of $100 \mathrm{y}$. This time difference is lower than the water residence time in the inner ocean $(150 \mathrm{y})$ because some ${ }^{231} \mathrm{~Pa}$ is scavenged in the inner ocean even if it is less effective than at the margin (Appendix B, Eq. B13).

These theoretical curves are compared with the AN5 profile (margin) and with the $\mathrm{Ce}-8$ profile $\left(12.75^{\circ} \mathrm{N}\right.$, $\left.173.23^{\circ} \mathrm{W}\right)\left(\right.$ Nozaki and Nakanishi, 1985) because ${ }^{231} \mathrm{~Pa}$ data are not available at the HOT Station. The Ce- 8 profile is also sampled in the subtropical gyre and it has a ${ }^{230} \mathrm{Th}$ profile very similar to the HOT station (but with less accurate data). Particulate ${ }^{231} \mathrm{~Pa}$ is not available but it generally represents less than $5 \%$ of the total ${ }^{231} \mathrm{~Pa}$. With the "Pacific 2" set of parameters (Table 1), the model correctly reproduces the margin profile down to $6000 \mathrm{~m}$. It correctly reproduces the inner ocean profile between the surface and $\sim 3000 \mathrm{~m}$ (Fig. 2e). The model fails to reproduce the lower part of the inner ocean profile where the concentration remains constant with depth and becomes close to the margin profile.

It must be noted that the subtropical gyre profiles are located in area with a seafloor depth of $6000 \mathrm{~m}$, but close to high relief with seafloor depth of $4000 \mathrm{~m}$ such as the Gilbert Ridge. Therefore, the circulation of the deep waters found at station Ce8 along the Gilbert ridge (Yanagimoto and Kawabe, 2007) may have enhanced locally the scavenging of ${ }^{231} \mathrm{~Pa}$ (as it can be seen also for ${ }^{230} \mathrm{Th}$ ). In addition, these waters flowing from the south may have been stripped from their ${ }^{231} \mathrm{~Pa}$ in the equatorial Pacific by the enhanced siliceous particulate flux. We also note that very low ${ }^{231} \mathrm{~Pa}$ concentrations were measured on the eastern margin of the Pacific Ocean (Anderson et al., 1983). Obviously, more data are required to further constrain this point.

\subsubsection{From boundary scavenging to boundary exchange}

Until now, only in situ produced nuclides have been discussed. I now consider the case of ${ }^{232} \mathrm{Th}$ that is derived from continental inputs. Dissolved ${ }^{232} \mathrm{Th}$ is produced by dissolution of lithogenic material. The main source of lithogenic particulate matter in the ocean is the river input in the coastal ocean (Table 2). It represents approximately 10 times the total atmospheric input. The flux of lithogenic aerosols at the margin is approximately 100 times higher than in the open ocean.

The average ${ }^{232} \mathrm{Th}$ content in lithogenic particles is of the order of $10 \mathrm{ppm} . \Phi_{m}$ and $\Phi_{I}$ are the fluxes of ${ }^{232} \mathrm{Th}$ released by dissolution of the incoming particles at the margin and in the inner ocean, assuming $1 \%$ of dissolution for both riverine and atmospheric particles (Arraes-Mescoff et al., 2001; RoyBarman et al., 2002). For $S_{i}, S_{m}, K_{i}$ and $K_{m}$ parameter, I use the same values as for ${ }^{230} \mathrm{Th}$ because isotopes of the same element are expected to have the same chemical behaviour in solution. The distribution of the dissolved ${ }^{232} \mathrm{Th}$ concentration with depth is then given by (Appendix A, Eq. A27a and b):

$$
\begin{aligned}
C_{d}^{i}= & \left(\frac{\left(1+K_{m}\right) \Phi_{m}}{K_{m} S_{m}}-\frac{\left(1+K_{i}\right) \Phi_{i}}{K_{i} S_{i}}\right) \frac{F}{S_{i} V_{i} K_{i}} \\
& \times z_{0} \times\left(1-e^{-\left(\frac{z}{z_{0}}\right)}\right)+\frac{\Phi_{i}}{K_{i} S_{i}}
\end{aligned}
$$

$$
C_{d}^{m}=\left(\frac{\left(1+K_{i}\right) \Phi_{i}}{K_{i} S_{i}}-\frac{\left(1+K_{m}\right) \Phi_{m}}{K_{m} S_{m}}\right) \frac{F}{S_{m} V_{m} K_{m}}
$$


Table 2. Lithogenic flux to the North Pacific Ocean.

\begin{tabular}{llll}
\hline & $\begin{array}{l}\text { Lithogenic } \\
\text { material flux } \\
\left(10^{12} \mathrm{~g} / \mathrm{y}\right)\end{array}$ & $\begin{array}{l}{ }^{232} \text { Th flux released } \\
\text { by dissolution**** } \\
\left(10^{6} \mathrm{pg} / \mathrm{m}^{2} / \mathrm{y}\right)\end{array}$ & $\begin{array}{l}\text { Nd flux released } \\
\text { by dissolution**** } \\
\left(10^{6} \mathrm{pg} / \mathrm{m}^{2} / \mathrm{y}\right)\end{array}$ \\
\hline Whole North Pacific atmospheric flux & $480^{*}$ & 1.6 & 4.8 \\
Central North Pacific atmospheric flux & $20^{* *}$ & 0.067 & 0.2 \\
lithogenic flux by river discharge & $6000^{* * *}$ & 33 & 100 \\
\hline
\end{tabular}

* Uematsu et al. (1985); ${ }^{* *}$ Duce et al. (1991); ${ }^{* * *}$ Milliman and Meade (1983); ${ }^{* * *}$ assuming $1 \%$ dissolution of lithogenic matter and considering that the North Pacific surface is $89 \times 10^{12} \mathrm{~m}^{2}$.

$$
\times z_{0} \times\left(1-e^{-\left(\frac{z}{z_{0}}\right)}\right)+\frac{\Phi_{m}}{K_{m} S_{m}}
$$

The modelled profiles are compared to the HOT profile (inner ocean) and to the compilation of Western Pacific margin data as dissolved ${ }^{232} \mathrm{Th}$ concentration is not available at station AN-5 (Nozaki and Yang, 1987). The modelled profiles do not reproduce precisely the data (Fig. $2 \mathrm{c}$ and $\mathrm{f}$ ), but they account for several important features: increasing ${ }^{232} \mathrm{Th}$ concentration with depth in the open ocean and decreasing ${ }^{232} \mathrm{Th}$ concentration with depth in the ocean margin. If there was no water exchange between the open ocean and the margin ( $F=0$ in Eq. 10a and b), both profiles should exhibit constant concentration with depth (Roy-Barman et al., 1996). In the open ocean, the increase of ${ }^{232} \mathrm{Th}$ concentration with depth is due to advection of ${ }^{232} \mathrm{Th}$-rich coastal water. At the ocean margin, the decrease ${ }^{232} \mathrm{Th}$ concentration with depth is due to the progressive flushing of the ${ }^{232}$ Th-rich margin water by ${ }^{232}$ Th-poor open ocean deep water.

A low water mixing rate allows a larger concentration difference between the open ocean and the ocean margin. However, it reduces the vertical concentration gradient in each reservoir. Given the limited ${ }^{232}$ Th data set, the ${ }^{232}$ Th concentration is much more sensitive to the water circulation pattern than uniformly in situ produced ${ }^{230} \mathrm{Th}$. The very low ${ }^{232} \mathrm{Th}$ content at the HOT station may be due to the reduced inflow of margin water to the centre of the gyre compared to the average open ocean (modelled reservoir). This would be consistent with the perfectly linear ${ }^{230} \mathrm{Th}$ profile that is not perfectly reproduced by the slightly curved ${ }^{230} \mathrm{Th}$ modelled profile of the Pacific 2 data set (Table 1, Fig. 2d).

Given that $\Phi_{i}$ is 2 orders of magnitude smaller than $\Phi_{m}$, setting $\Phi_{i}=0$ does not change the modelled ${ }^{232} \mathrm{Th}$ profile of the inner ocean significantly (not shown). This means that most ${ }^{232} \mathrm{Th}$ in the inner ocean is advected from the ocean margin. Hence, the ocean margin acts both as a net sink for the ${ }^{230}$ Th produced in the inner ocean (boundary scavenging) but also as a net source of ${ }^{232} \mathrm{Th}$ for the open ocean. This illustrates the concept of boundary exchange developed with $\mathrm{Nd}$ isotopes where ocean margins play simultaneously the role of source and sink for a chemical element (Lacan and Jeandel, 2005).
The effect of the dissolution of the lithogenic inputs to the N. Pacific on the Nd isotopic composition of the Pacific deep water can be evaluated. Assuming that the lithogenic $\mathrm{Nd}$ is dissolved at the same extent as ${ }^{232} \mathrm{Th}(1 \%)$, a total flux of $\mathrm{Nd}$ $F_{\mathrm{Nd}-\text { litho }}=1.9 \times 10^{9} \mathrm{~g} / \mathrm{y}$ is released in the North Pacific margin. The average $\mathrm{Nd}$ isotopic composition is $\varepsilon_{\mathrm{Nd}-\mathrm{litho}} \approx+6 \pm 4$ (Jeandel et al., 2007). This $\mathrm{Nd}$ is mixed with the $\mathrm{Nd}$ carried from the south Pacific by the thermohaline circulation. Using a water flow of $36 \times 10^{6} \mathrm{~m}^{3} / \mathrm{s}$ (Table 1 ) and an average dissolved $\mathrm{Nd}$ concentration of $4 \mathrm{ng} / \mathrm{l}$ in seawater, we obtain an input of $F_{\mathrm{Nd}-\text { southPacific }}=3.8 \times 10^{9} \mathrm{~g} / \mathrm{y}$ with an average $\mathrm{Nd}$ isotopic composition $\varepsilon_{\mathrm{Nd}-\text { southPacific }} \approx-8$ (Jeandel et al., 2007). The Nd isotopic composition of the Pacific deep water is given by

$\varepsilon_{\mathrm{Nd}-\text { northPac }}=\frac{F_{\mathrm{Nd}-\text { litho }} \times \varepsilon_{\mathrm{Nd}-\text { litho }}+F_{\mathrm{Nd}-\text { South Pac }} \times \varepsilon_{\mathrm{Nd}-\text { South Pac }}}{F_{\mathrm{Nd}-\text { litho }}+F_{\mathrm{Nd}-\text { South Pac }}}$

I obtain $\varepsilon_{\mathrm{Nd}-\text { northPac }} \approx-3.7 \pm 1.2$, in very gross agreement with the average value of the North Pacific $\left(\varepsilon_{\mathrm{Nd}} \approx-4.5\right.$ (Arsouze et al., 2007)). It suggests that dissolution of lithogenic particles at the ocean margin provides a suitable source of $\mathrm{Nd}$ to explain the change of $\mathrm{Nd}$ isotopic composition as already proposed by (Lacan and Jeandel, 2005). Hence, simultaneous measurement of $\mathrm{Nd}$ and $\mathrm{Th}$ profiles could improve the understanding of the boundary exchange process by coupling a source tracer $(\mathrm{Nd})$ with a chronometer $(\mathrm{Th})$. Using $\mathrm{Nd}$ and Th as analogs for the insoluble elements such as iron will provide strong constraints on the inputs of micronutrients in the ocean.

\subsection{Arctic Ocean}

\subsubsection{Th}

The first ${ }^{230} \mathrm{Th}$ data in the Arctic Ocean revealed unusually high ${ }^{230} \mathrm{Th}$ concentrations that were explained by the very low particle flux in this area covered by sea-ice (Bacon et al., 1989). Subsequent works demonstrated that lower concentrations occurred, in particular close to the shelf zones (Cochran et al., 1995; Edmonds et al., 1998, 2004; Scholten 


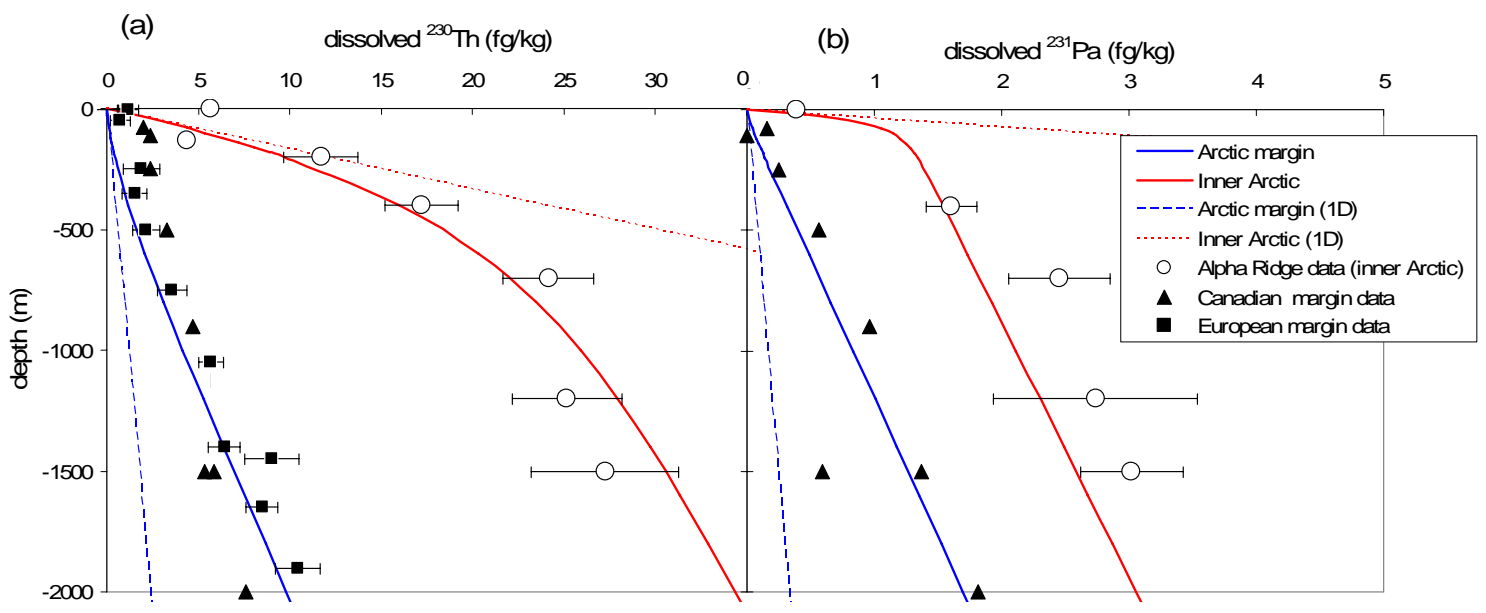

Fig. 3. Modelled profiles and comparison with data for the Arctic Ocean. See Table 1 for model parameters. "1-D" curves are obtained for the Arctic margin and inner Arctic Ocean by setting $F=0$ and keeping all the other parameters identical.

et al., 1995). The reversible scavenging model and the advection mixing model have generally failed to represent the low ${ }^{230} \mathrm{Th}$ concentrations in deep waters when using reasonable ventilation rates (Scholten et al., 1995). The ventilation rate on the Arctic Ocean is slow (Schlosser et al., 1995; Tanhua et al., 2009). In the Nansen Basin, the ventilation ages are of the order of a few years to decades for surface and halocline waters, $100 \mathrm{y}$ for intermediate waters $(500-1500 \mathrm{~m}), 200 \mathrm{y}$ for deep water (1500-2500 m) and $300 \mathrm{y}$ for bottom waters ( $>2500 \mathrm{~m}$ ) (Schlosser et al., 1995). In the Canadian basin the ventilation of the intermediate, deep and bottom water is even slower, with a ventilation age of $450 \mathrm{y}$ below $2000 \mathrm{~m}$ (Anderson et al., 1999; Schlosser et al., 1997). Over the Alpha ridge, the $200 \mathrm{~m}$ Atlantic water has CFC and ${ }^{137} \mathrm{Cs}$ ages of at least $30 \mathrm{y}$ (Wallace and Moore, 1985). Deeper waters have very low anthropogenic tracer levels indicating long ventilation ages. It follows that the water ventilation is always slow compared to particulate transport. In the following discussion, I will neglect ventilation and just focus on the role of particle scavenging and horizontal advection on ${ }^{230} \mathrm{Th}$ transport.

During the 1990s, the Arctic Ocean has experienced significant changes. An increase of the warm Atlantic inflow was recorded in the Nansen, Amundsen and Makarov Basins. The Canadian basin remains relatively less affected. As the model assumes a steady state circulation, I compare the model with data collected during the 1980s or early 1990s in the European Basin and data collected during the 1990s and later for the Canada Basin. The inner ocean is represented by the CESAR station $\left(85^{\circ} 50^{\prime} \mathrm{N}, 108^{\circ} 50^{\prime} \mathrm{W}\right)$ over the permanently ice-covered Alpha ridge (Bacon et al., 1989). I take as reference for the margin ocean, stations 287 $\left(81^{\circ} 40^{\prime} \mathrm{N}, 30^{\circ} 48^{\prime} \mathrm{E}\right)$ and $423\left(81^{\circ} 19.9^{\prime} \mathrm{N}, 15^{\circ} 18.9^{\prime} \mathrm{E}\right)$ sampled along the slope of the Nansen basin (Cochran et al., 1995)) in agreement with circulations schemes between the
Alpha Ridge and the Nansen Basin (Rudels et al., 1994). As ${ }^{231} \mathrm{~Pa}$ was not measured at these stations, I also use a station $\left(72^{\circ} 32.59 \mathrm{~N}, 143^{\circ} 49.89 \mathrm{~W}\right)$ from the Canada basin with similar ${ }^{230} \mathrm{Th}$ concentration (Edmonds et al., 1998).

I consider waters above $2000 \mathrm{~m}$ because at greater depth the situation is complicated by the presence of oceanic ridges. The margin-inner ocean limit is set at the $2000 \mathrm{~m}$ isobath. The volume of the ocean margin (including marginal seas) is $1.55 \times 10^{6} \mathrm{~km}^{3}$ and the central Arctic Ocean above $2000 \mathrm{~m}$ is $6.5 \times 10^{6} \mathrm{~km}^{3}$. Surprisingly the margin/open ocean ratio is lower for the Arctic (1:4) than for the Pacific Ocean (1:3). This is because the shelves cover about $53 \%$ of the Arctic Ocean area, but contain only about $5 \%$ of the total Arctic Ocean volume (Jakobsson, 2002).

The transport is assumed to occur by eddy diffusion along isopycnal surfaces. An eddy diffusion coefficient of $K_{H}=1.5 \times 10^{7} \mathrm{~cm}^{2} / \mathrm{s}$ (Carmack et al., 1997) and a distance of $1500 \mathrm{~km}$ between the CESAR Station and the European shelf combined in Eq. (9) produce a mixing time $\Delta t \approx 40 \mathrm{y}$. It represents the time required for the water of the ocean margin to reach the inner ocean. Therefore, we set water residence time: $\tau_{i}=40 \mathrm{y}, \tau_{m}=10 \mathrm{y}$.

Knowing the concentration profiles, $K_{i}$ and $K_{m}$ from field data, the settling speeds are adjusted to obtain the best fit of the data (Table 1, Fig. 3a). Just like for ${ }^{231} \mathrm{~Pa}$ in the Pacific, the "margin" and "inner ocean" ${ }^{230}$ Th profiles become parallel at great depth. Below $500 \mathrm{~m}$, the concentration difference between the 2 profiles at a given depth is equal to $20 \mathrm{fg} / \mathrm{l}$. This difference is due to ${ }^{230} \mathrm{Th}$ ingrowth while water flows from the margin to the basin centre. Dividing this concentration difference by the production rate of ${ }^{230} \mathrm{Th}(0.54 \mathrm{fg} / \mathrm{l} / \mathrm{y})$ yields a time difference of $40 \mathrm{y}$. This is equal to the residence time of the water in the inner ocean because the scavenging rate is very low in the inner ocean and the water residence time is too short for the deep ${ }^{230} \mathrm{Th}$ concentration to reach 
the linear equilibrium established in the shallow waters (Appendix B, Eq. B13).

The boundary scavenging profile model proposed here is the first model that accounts for the non-linear shape of the CESAR station ${ }^{230} \mathrm{Th}$ profile (remembering that the deep water ventilation is too slow to account for the shape of the profile). Similarly, margin-inner ocean interactions can explain why ${ }^{230} \mathrm{Th}$ concentrations lower than predicted with the 1$\mathrm{D}$ model or the advection mixing model (using reasonable ventilation time) are found in the deep water of the Nansen, Amundsen and Makarov basins (Scholten et al., 1995).

Another important result of the model comes from the calculation of the ${ }^{230} \mathrm{Th}$ particulate flux to the sediment. At $2000 \mathrm{~m}$, the ${ }^{230} \mathrm{Th}$ particulate flux $\left(S \times C_{p}\right)$ represents $409 \%$ of the in situ production in the overlying water column at the margin and only $29 \%$ in the inner ocean. This clearly shows that ${ }^{230} \mathrm{Th}$ may be strongly affected by boundary scavenging. An obvious consequence of this particle flux effect is that the particle settling velocity at the margin cannot be evaluated correctly with the 1-D model although the ${ }^{230} \mathrm{Th}$ profile increases linearly with depth. Using the 1-D model, the settling speed of the particles at the Nansen basin margin is $300 \mathrm{~m} / \mathrm{y}$ whereas it is $600 \mathrm{~m} / \mathrm{y}$ in the open Nansen basin, where one would expect a lower settling velocity (Cochran et al., 1995). In fact, one would expect a higher settling velocity rate of the particulate matter at the margin where the concentration of biological and lithogenic particles is the highest (and as a consequence the dissolved ${ }^{230} \mathrm{Th}$ concentration the lowest). The proposed explanation was that sediment resuspension could account for the lower calculated settling velocity at the margin. In fact, with the 1-D model, the settling velocity just depends on the particulate ${ }^{230} \mathrm{Th}$ concentration:

$S=(P \times d) / 230 \mathrm{Th}_{p}$

where $d$ is the water column height, so that, at a given depth, a high particulate ${ }^{230} \mathrm{Th}$ concentration always gives a low velocity.

With the boundary scavenging profile model, I estimate that the particle settling velocity is of the order of $1000 \mathrm{~m} / \mathrm{y}$. This value is much larger than the value $(300 \mathrm{~m} / \mathrm{y}$ based on the 6 y particulate Th residence time over a $2000 \mathrm{~m}$ water column calculated by (Cochran et al., 1995)) estimated with the 1-D-model because the sinking particulate matter must scavenge both the in situ production and the net input transported from the open ocean. This lateral transport is not represented in the 1-D model but it was already considered with the boundary scavenging box model of the Pacific Ocean (Anderson et al., 1983). The added value of the boundary scavenging profile model is to stress that a linear ${ }^{230} \mathrm{Th}$ profile (such as the profiles measured on the Arctic Ocean margins) does not guarantee that lateral transport can be neglected, as already shown by the study of thorium isotopes on and around the Kerguelen plateau (Venchiarutti et al., 2008).

As a consequence, a strong contrast in the accumulation rate of sedimentary ${ }^{230} \mathrm{Th}$ should exist between the open Arc- tic Ocean and its margins. Early evaluations of the ${ }^{230} \mathrm{Th}$ in arctic sediments suggested a strong ${ }^{230} \mathrm{Th}$ deficiency in the arctic sediments (Huh et al., 1997). A recent re-evaluation of the core ages has reduced this deficiency (Hoffmann and McManus, 2007) and demonstrated that high ${ }^{230} \mathrm{Th}$ accumulation rates $(\sim 2$ times the local production rate) occur in the vicinity of the Chukchi shelf during the Holocene. ${ }^{230} \mathrm{Th}$ accumulation rates equivalent to the overlying production rate are observed towards the open ocean. Cores from the areas of the lowest sediment accumulation rates have not been measured in (Hoffmann and McManus, 2007).

\subsection{2 ${ }^{231} \mathbf{P a}$}

In order to obtain modelled profiles consistent with the available data (Fig. 3b), I use the settling speed obtained with ${ }^{230} \mathrm{Th}$ in the previous section, $K_{i}^{P a} \approx K_{i}^{T h} / 10$ in the inner Arctic Ocean (similar to the inner the Pacific ocean) and $K_{m}^{P a} \approx K_{m}^{T h} / 3$ for the Arctic margin (slightly larger ${ }^{231} \mathrm{~Pa} /{ }^{230} \mathrm{Th}$ fractionation than in the Pacific margin) in agreement with the available data (Moran et al., 2005; Scholten et al., 1995). As already noted for ${ }^{230} \mathrm{Th}$, a linear ${ }^{231} \mathrm{~Pa}$ profile at the margin does not demonstrate that ${ }^{231} \mathrm{~Pa}$ transport is dominated by vertical transport by particles rather than by lateral transport as proposed by (Edmonds et al., 1998).

A salient feature of the ${ }^{231} \mathrm{~Pa}^{2}{ }^{230} \mathrm{Th}$ fractionation in arctic sediments is that almost all ${ }^{231} \mathrm{~Pa} /{ }^{230} \mathrm{Th}$ ratios in top-core sediments are lower than or equal to the production ratio of these nuclides in seawater even in ocean margin sites (Moran et al., 2005; Scholten et al., 1995). It was proposed that $40 \%$ of the Pa produced in the Arctic Ocean is exported in the Norwegian and Greenland seas through the Fram Straight, but sediments of the and Greenland sea do not show the high ${ }^{231} \mathrm{~Pa} /{ }^{230} \mathrm{Th}$ ratios that would be expected in case of arrival of $\mathrm{Pa}$ from the Arctic Ocean. The boundary scavenging profile model suggests another process that could contribute to the lack of high ${ }^{231} \mathrm{~Pa} /{ }^{230} \mathrm{Th}$ ratio in the sediments of the Arctic margins. The modelled ${ }^{231} \mathrm{~Pa} /{ }^{230} \mathrm{Th}$ ratio in the particles of the open Arctic Ocean at $2000 \mathrm{~m}$ (and thus the ratio expected in the open ocean sediments) is below the production ratio, but the ${ }^{231} \mathrm{~Pa} /{ }^{230} \mathrm{Th}$ ratio in the particles of the Arctic margin at $2000 \mathrm{~m}$ are only slightly higher than the production ratio (Table 1). This is because the scavenging rate of ${ }^{231} \mathrm{~Pa}$ and ${ }^{230} \mathrm{Th}$ is so low in the open Arctic Ocean that most nuclides are scavenged at the ocean margin so that little ${ }^{231} \mathrm{~Pa} /{ }^{230} \mathrm{Th}$ fractionation occurs compared to the production ratio. The difference with other oceans is that in the Arctic there could be a substantial lateral transport of ${ }^{230} \mathrm{Th}$ from the open ocean to the margins.

\subsubsection{Comparison with other models}

Following the seminal work of the 1-D scavenging model, various models have been proposed to describe the impact of 
lateral transport on ${ }^{230} \mathrm{Th}$ and ${ }^{231} \mathrm{~Pa}$ profiles. In the South Atlantic, the strong upwelling of the deep water masses cannot be neglected so that the ${ }^{230} \mathrm{Th}$ and ${ }^{231} \mathrm{~Pa}$ profiles in this area were modelled by considering the transport of the nuclides by a reversible scavenging and the homogeneous advection of a water mass with a constant concentration throughout the water column (Rutgers van der Loeff and Berger, 1993). This model is now currently used to model ${ }^{230} \mathrm{Th}$ and ${ }^{231} \mathrm{~Pa}$ profiles when upwelling or ventilation are important (Coppola et al., 2006; Moran et al., 2002; Roy-Barman et al., 2002). In particular, this model accounts for the low $\mathrm{Pa}$ and Th concentrations found in the deep waters of the Atlantic due to the presence of recently ventilated waters that have lost their Th and Pa by scavenging when they were at the surface (Scholten et al., 2008). It must be noted that boundary scavenging can produce Th and Pa profiles with low concentrations in the deep waters, a feature only modelled in the case of deep water ventilation until now. As a consequence, further work will have to consider the combined role of ventilation and boundary scavenging on Th and Pa profiles in the deep waters and the possible impact of boundary scavenging on the estimate of the ventilation rate based on $\mathrm{Pa}$ and $\mathrm{Th}$ data.

Recently, the effect of lateral transport was taken into account in a simple modelling of thorium isotopes in order to evaluate the settling speed of marine particles on the Kerguelen plateau that is a place or high biological productivity (due to an iron-induced bloom) surrounded by the HNLC Southern Ocean. In this model, open ocean water with a ${ }^{230} \mathrm{Th}$ concentration increasing linearly with depth is advected on the plateau. Advection and reversible scavenging on the plateau were used to explain the ${ }^{230} \mathrm{Th}$ concentration profile on the plateau (Venchiarutti et al., 2008). The Kerguelen plateau model is a particular case of the boundary scavenging profile model. In the case of the Kerguelen plateau, the ${ }^{230} \mathrm{Th}$ content of the open ocean water is considered as a fixed parameter and the scavenging conditions on the plateau have no feedback on this profile, because it seems reasonable to consider that the ${ }^{230} \mathrm{Th}$ content of the open Southern Ocean is not significantly influenced by the enhanced scavenging on the small Kerguelen plateau. On the contrary in the boundary scavenging profile model, the open ocean concentration is not fixed but it may be affected by the scavenging on the margins. Mathematically, the Kerguelen plateau model is equivalent to the boundary scavenging profile model with infinitely large open ocean volume (Appendix B, Sect. B4.). Contrary to the Kerguelen plateau model described above, the boundary scavenging profile model takes into account advection and scavenging to evaluate the ${ }^{230} \mathrm{Th}$ profiles simultaneously in the inner ocean and at the margin.

Regional and global circulation models coupled with biogeochemical models of various complexities are used to study the impact of circulation on the distribution of ${ }^{230} \mathrm{Th}$ and ${ }^{231} \mathrm{~Pa}$ in the ocean as well as the possible constraints brought by ${ }^{230} \mathrm{Th}$ and ${ }^{231} \mathrm{~Pa}$ on the thermohaline circula- tion (Dutay et al., 2009; Henderson et al., 1999, Siddall et al., 2005, 2007, 2008). These models successfully represent the preferential accumulation of particle reactive nuclides in the sediments of ocean margins but they have not been used directly to evaluate the impact of boundary scavenging on ${ }^{230} \mathrm{Th}$ and ${ }^{231} \mathrm{~Pa}$ distribution in the water column. It must be noted that due to the paucity of data, these models are often underconstrained to discuss ${ }^{230} \mathrm{Th}$ or ${ }^{231} \mathrm{~Pa}$ in a given region. Recently, (Marchal et al., 2007) used a constant and homogeneous particle flux over the whole Atlantic Ocean in order to use ${ }^{230} \mathrm{Th}$ as tracer of the thermohaline circulation. With regard to these sophisticated models, the present work underlines that the particle effect found at the ocean margin is not only due to a higher concentration of particulate matter but also to a faster settling rate of these particles, probably through aggregation/disagregation with the large settling particles. It stresses that more complex particle dynamics has to be used for these coupled physical-biogeochemical models as proposed by (Dutay et al., 2009). This would be particularly important for example to take into account geographical and/or temporal evolution of the ballasting effect.

\section{Conclusions}

The aim of the boundary scavenging profile model is not to describe precisely the Th and Pa profiles of any complicated "real" situation. It is rather to provide a simple theoretical framework where some effects of lateral transport on Th and Pa profiles can be evaluated and tested against observations. One of its important outputs is that a "more or less" linear ${ }^{230} \mathrm{Th}$ profile does not necessarily imply that advection is negligible as assumed in the 1D model and implies a re-evaluation of the ${ }^{230} \mathrm{Th}$-based mean settling speed of particulate matter particularly in the coastal area. With the availability of high precision data measured by Thermal Ionisation Mass Spectrometry or by Induced Coupled Plasma Mass Spectrometry, it becomes obvious that the non-linear ${ }^{230} \mathrm{Th}$ profiles are more the rule than the exception even though linear profiles do exist (Roy-Barman et al., 1996). Until now, these non-linear profiles were generally attributed to upwelling or water mass ventilation. The model proposed in the present article allows a quantitative assessment of the effect of boundary scavenging which was suspected to produce non-linear profiles too. More generally, it allows a first order quantification of the effect of oceanic circulation on $\mathrm{Pa}$ and $\mathrm{Th}$ distribution in the water columns of areas with distinct scavenging conditions (margin/open ocean, subtropical gyre/equatorial area (Broecker, 2008), subtropical gyre/subpolar gyre (Taguchi et al., 1989)). This model should be useful for the numerous $\mathrm{Pa}$-Th studies launched in the framework of the GEOTRACES program. 


\section{Appendix A}

\section{Resolution of the equations}

\section{A1 General solution}

In the boundary scavenging profile model, the margin and the ocean interior works symmetrically (they only differ by the value of the constants $S$ and $K$ ), so that Eq. (3a) and (3b) are symmetrical with respect to the margin and the open ocean. Therefore, it is sufficient to solve these equations for $C_{d}^{i}$ to be able to deduce $C_{d}^{m}$ by symmetry. These 2 equations are coupled by the lateral transport term. Using Eq. (3b), $C_{d}^{m}$ can be expressed as a function of the other variables:

$C_{d}^{m}=\frac{S_{i} V_{i} K_{i}}{F\left(1+K_{m}\right)} \frac{d C_{d}^{i}}{d z}-\frac{P V_{i}}{F\left(1+K_{m}\right)}+\frac{\left(1+K_{i}\right)}{\left(1+K_{m}\right)} C_{d}^{i}$

Derivating A1, gives the expression:

$$
\begin{aligned}
\frac{d C_{d}^{m}}{d z} & =\frac{d\left(\frac{S_{i} V_{i} K_{i}}{F\left(1+K_{m}\right)} \frac{d C_{d}^{i}}{d z}-\frac{P V_{i}}{F\left(1+K_{m}\right)}+\frac{\left(1+K_{i}\right)}{\left(1+K_{m}\right)} C_{d}^{i}\right)}{d z} \\
& =\frac{S_{i} V_{i} K_{i}}{F\left(1+K_{m}\right)} \frac{d^{2} C_{d}^{i}}{d z^{2}}+\frac{\left(1+K_{i}\right)}{\left(1+K_{m}\right)} \frac{d C_{d}^{i}}{d z}
\end{aligned}
$$

Combining Eqs. (A2) and (3a), we obtain:

$$
\begin{aligned}
& -S_{m} K_{m}\left(\frac{S_{i} V_{i} K_{i}}{F\left(1+K_{m}\right)} \frac{d^{2} C_{d}^{i}}{d z^{2}}+\frac{\left(1+K_{i}\right)}{\left(1+K_{m}\right)} \frac{d C_{d}^{i}}{d z}\right)+P \\
& +\frac{F}{V_{m}}\left[\left(1+K_{i}\right) C_{d}^{i}-\left(1+K_{m}\right)\left(\frac{S_{i} V_{i} K_{i}}{F\left(1+K_{m}\right)} \frac{d C_{d}^{i}}{d z}-\frac{P V_{i}}{F\left(1+K_{m}\right)}+\frac{\left(1+K_{i}\right)}{\left(1+K_{m}\right)} C_{d}^{i}\right)\right] \\
& =0
\end{aligned}
$$

which simplifies into:

$$
\begin{aligned}
& -\frac{S_{i} S_{m} K_{i} K_{m} V_{i}}{F\left(1+K_{m}\right)} \frac{d^{2} C_{d}^{i}}{d z^{2}} \\
& -\left[S_{m} K_{m} \frac{\left(1+K_{i}\right)}{\left(1+K_{m}\right)}+\frac{S_{i} V_{i} K_{i}}{V_{m}}\right] \frac{d C_{d}^{i}}{d z}+P\left(1+\frac{V_{i}}{V_{m}}\right)=0
\end{aligned}
$$

Equation (A4) can be written as:

$a \frac{d^{2} C_{d}^{i}}{d z^{2}}+b \frac{d C_{d}^{i}}{d z}+c=0$

with

$a=-\frac{S_{i} S_{m} K_{i} K_{m} V_{i}}{F\left(1+K_{m}\right)}$

$b=-\left[S_{m} K_{m} \frac{\left(1+K_{i}\right)}{\left(1+K_{m}\right)}+\frac{S_{i} V_{i} K_{i}}{V_{m}}\right]$

$c=P\left(1+\frac{V_{i}}{V_{m}}\right)$

Integrating this equation a first time, we obtain:

$a \frac{d C_{d}^{i}}{d z}+b C_{d}^{i}=-c z+d_{1}$ where $d_{1}$ is an integration constant. The solution of Eq. (A5) can be written:

$C_{d}^{i}=f e^{-\left(\frac{b}{a}\right) z}$

here $f$ is a function of $z$. Substituting this expression in Eq. (A7), we obtain:

$a \frac{d f}{d z} e^{-\left(\frac{b}{a} z\right)}=-c z+d_{1}$

so that:

$\frac{d f}{d z}=-\frac{c z+d_{1}}{a} e^{\left(\frac{b}{a}\right) z}$

The primitive of this function can be written as

$f=\left(\frac{-c}{b} z+\frac{a c+d_{1} b}{b^{2}}\right) e^{\left(\frac{b}{a}\right) z}+d_{2}$

where $d_{2}$ is an integration constant. Substituting Eq. (A11) in Eq. (A8), we obtain:

$C_{d}^{i}=-\frac{c}{b} z+\frac{a c+d_{1} b}{b^{2}}+d_{2} e^{-\left(\frac{b}{a}\right) z}$

It is now necessary to determine the value of $d_{1}$ and $d_{2}$ with 2 boundary conditions. At $z=0$, the vertical particulate flux $\left(C_{p} \times \mathrm{S}\right)$ must be equal to the atmospheric input $(\Phi)$. It follows that

$C_{p}^{m}(z=0)=\frac{\Phi_{m}}{S_{m}}$

$C_{p}^{i}(z=0)=\frac{\Phi_{i}}{S_{i}}$

and because $C_{p}=K C_{d}$ (Eq. 2):

$C_{d}^{m}(z=0)=\frac{\Phi_{m}}{K_{m} S_{m}}$

$C_{d}^{i}(z=0)=\frac{\Phi_{i}}{K_{i} S_{i}}$

For the inner ocean, combining Eq. (A12) and Eq. (A13d) for $z=0$ gives:

$C_{d}^{i}(z=0)=+\frac{a c+d_{1} b}{b^{2}}+d_{2}=\frac{\Phi_{i}}{K_{i} S_{i}}$

For the margin, combining Eq. (A1) and Eq. (A12), gives

$$
\begin{aligned}
C_{d}^{m}= & \frac{S_{i} V_{i} K_{i}}{F\left(1+K_{m}\right)} \frac{d\left(-\frac{c}{b} z+\frac{a c+d_{1} b}{b^{2}}+d_{2} e^{-\left(\frac{b}{a}\right) z}\right)}{d z}-\frac{P V_{i}}{F\left(1+K_{m}\right)} \\
& +\frac{\left(1+K_{i}\right)}{\left(1+K_{m}\right)}\left(-\frac{c}{b} z+\frac{a c+d_{1} b}{b^{2}}+d_{2} e^{-\left(\frac{b}{a}\right) z}\right)
\end{aligned}
$$

Calculating the derivative terms yield

$$
\begin{aligned}
C_{d}^{m}= & \frac{S_{i} V_{i} K_{i}}{F\left(1+K_{m}\right)}\left(-\frac{c}{b}-\left(\frac{b}{a}\right) d_{2} e^{-\left(\frac{b}{a}\right) z}\right)-\frac{P V_{i}}{F\left(1+K_{m}\right)} \\
& +\frac{\left(1+K_{i}\right)}{\left(1+K_{m}\right)}\left(-\frac{c}{b} z+\frac{a c+d_{1} b}{b^{2}}+d_{2} e^{-\left(\frac{b}{a}\right) z}\right)
\end{aligned}
$$


at $z=0$, combining Eq. (A16) and Eq. (A13c), yields:

$$
\begin{aligned}
C_{d}^{m}(z=0)= & \frac{S_{i} V_{i} K_{i}}{F\left(1+K_{m}\right)}\left(-\frac{c}{b}-\left(\frac{b}{a}\right) d_{2}\right) \\
& -\frac{P V_{i}}{F\left(1+K_{m}\right)}+\frac{\left(1+K_{i}\right)}{\left(1+K_{m}\right)}\left(\frac{a c+d_{1} b}{b^{2}}+d_{2}\right) \\
& =\frac{\Phi_{m}}{K_{m} S_{m}}
\end{aligned}
$$

Introducing Eq. (A14) in Eq. (A17), allows eliminating $d_{1}$ :

$\frac{S_{i} V_{i} K_{i}}{F\left(1+K_{m}\right)}\left(-\frac{c}{b}-\left(\frac{b}{a}\right) d_{2}\right)-\frac{P V_{i}}{F\left(1+K_{m}\right)}$

$+\frac{\left(1+K_{i}\right)}{\left(1+K_{m}\right)}\left(\frac{\Phi_{i}}{K_{i} S_{i}}\right)=\frac{\Phi_{m}}{K_{m} S_{m}}$

Equation (A18) allows determining $d_{2}$ :

$d_{2}=-\left\{\frac{P}{S_{i} K_{i}}+\frac{c}{b}+\left(\frac{\left(1+K_{m}\right) \Phi_{m}}{K_{m} S_{m}}-\frac{\left(1+K_{i}\right) \Phi_{i}}{K_{i} S_{i}}\right) \frac{F}{S_{i} V_{i} K_{i}}\right\}\left(\frac{a}{b}\right)$

Combining Eq. (A12) with Eq. (A13d) at $z=0$, gives:

$C_{d}^{i}(z=0)=\frac{a c+d_{1} b}{b^{2}}+d_{2}=\frac{\Phi_{i}}{K_{i} S_{i}}$

so that

$$
\begin{aligned}
C_{d}^{i} & =-\frac{c}{b} z+\left(\frac{\Phi_{i}}{K_{i} S_{i}}-d_{2}\right)+d_{2} e^{-\left(\frac{b}{a}\right) z} \\
& =-\frac{c}{b} z+d_{2}\left(e^{-\left(\frac{b}{a}\right) z}-1\right)-\frac{\Phi_{i}}{K_{i} S_{i}}
\end{aligned}
$$

We note that

$$
\begin{aligned}
\frac{b}{a} & =\frac{\left[S_{m} K_{m} \frac{\left(1+K_{i}\right)}{\left(1+K_{m}\right)}+\frac{S_{i} V_{i} K_{i}}{V_{m}}\right]}{\frac{S_{i} S_{m} K_{i} K_{m} V_{i}}{F\left(1+K_{m}\right)}} \\
& =\frac{F}{V_{i}} \frac{\left(1+K_{i}\right)}{S_{i} K_{i}}+\frac{F}{V_{m}} \frac{\left(1+K_{m}\right)}{S_{m} K_{m}}
\end{aligned}
$$

So $z_{0}$ is defined as:

$z_{0}=\left(\frac{F}{V_{i}} \frac{\left(1+K_{i}\right)}{S_{i} K_{i}}+\frac{F}{V_{m}} \frac{\left(1+K_{m}\right)}{S_{m} K_{m}}\right)^{-1}$

$1 / z_{0}$ is the e-folding term of the vertical evolution of the slope of the concentrations $(\mathrm{d} C / \mathrm{d} z)$ and of the concentrations themselves (Eqs. A5 and A7). $z_{0}$ represents a depth below which lateral mixing becomes significant compared to particulate transport.

$$
\begin{aligned}
\frac{c}{b} & =-\frac{\left(P+P \frac{V_{i}}{V_{m}}\right)}{S_{m} K_{m} \frac{\left(1+K_{i}\right)}{\left(1+K_{m}\right)}+\frac{S_{i} V_{i} K_{i}}{V_{m}}} \\
& =-\frac{1}{\left(1+K_{i}\right)} \frac{P\left(V_{m}+V_{i}\right)}{\frac{S_{m} K_{m} V_{m}}{\left(1+K_{m}\right)}+\frac{S_{i} V_{i} K_{i}}{\left(1+K_{i}\right)}}
\end{aligned}
$$

We note:

$\sigma_{\infty}=\frac{P\left(V_{m}+V_{i}\right)}{\frac{S_{m} K_{m} V_{m}}{\left(1+K_{m}\right)}+\frac{S_{i} V_{i} K_{i}}{\left(1+K_{i}\right)}}$ $\sigma_{\infty}$ represents the slope of the dissolved + particulate ${ }^{230} \mathrm{Th}$ concentration versus depth profiles at great depth for the margin and the inner ocean.

Introducing Eq. (A19) and (A21)-(A24) in Eq. A20b gives the final expression of $C_{d}^{i}$ :

$$
\begin{aligned}
& C_{d}^{i}=\frac{\sigma_{\infty}}{\left(1+K_{i}\right)} \times z+\frac{\Phi_{i}}{K_{i} S_{i}} \\
& +\left(\frac{P}{S_{i} K_{i}}-\frac{\sigma_{\infty}}{\left(1+K_{i}\right)}+\left(\frac{\left(1+K_{m}\right) \Phi_{m}}{K_{m} S_{m}}-\frac{\left(1+K_{i}\right) \Phi_{i}}{K_{i} S_{i}}\right) \frac{F}{S_{i} V_{i} K_{i}}\right) \\
& \times z_{0} \times\left(1-e^{-\left(\frac{z}{z_{0}}\right)}\right)
\end{aligned}
$$

The term $\frac{1}{\left(1+K_{i}\right)}$ converts total ${ }^{230} \mathrm{Th}$ into dissolved ${ }^{230} \mathrm{Th}$ in the ocean interior. Notting that the problem is mathematically symmetrical with regard to the ocean margin and the inner ocean, the concentration in the coastal ocean is given by:

$$
\begin{aligned}
& C_{d}^{m}=\frac{\sigma_{\infty}}{\left(1+K_{m}\right)} \times z+\frac{\Phi_{m}}{K_{m} S_{m}} \\
& +\left(\frac{P}{S_{m} K_{m}}-\frac{\sigma_{\infty}}{\left(1+K_{m}\right)}+\left(\frac{\left(1+K_{i}\right) \Phi_{i}}{K_{i} S_{i}}-\frac{\left(1+K_{m}\right) \Phi_{m}}{K_{m} S_{m}}\right) \frac{F}{S_{m} V_{m} K_{m}}\right) \\
& \times z_{0} \times\left(1-e^{\left.-\left(\frac{z}{z_{0}}\right)\right)}\right.
\end{aligned}
$$

\section{A2 Solution for in situ produced nuclide $\left({ }^{230} \mathbf{T} \mathbf{h}_{x s}\right.$ and $\left.{ }^{231} \mathbf{P a}_{x s}\right)$}

For ${ }^{230} \mathrm{Th}$ and ${ }^{231} \mathrm{~Pa}$, we are interested by their in situ produced fraction represented by ${ }^{230} \mathrm{Th}_{x s}$ and ${ }^{231} \mathrm{~Pa}_{x s}$. Therefore, the atmospheric inputs are taken equal to zero $\left(\Phi_{i}=\Phi_{m}=0\right)$. With these conditions the profiles are given by:

$$
\begin{aligned}
& C_{d}^{i}=\frac{\sigma_{\infty}}{\left(1+K_{i}\right)} \times z+\left(\frac{P}{S_{i} K_{i}}-\frac{\sigma_{\infty}}{\left(1+K_{i}\right)}\right) \\
& \times z_{0} \times\left(1-e^{-\left(\frac{z}{z_{0}}\right)}\right) \\
& C_{d}^{m}=\frac{\sigma_{\infty}}{\left(1+K_{m}\right)} \times z+\left(\frac{P}{S_{m} K_{m}}-\frac{\sigma_{\infty}}{\left(1+K_{m}\right)}\right) \\
& \times z_{0} \times\left(1-e^{-\left(\frac{z}{z_{0}}\right)}\right)
\end{aligned}
$$

\section{A3 Solution for external inputs only $\left({ }^{232} \mathrm{Th}\right)$}

Dissolved ${ }^{232} \mathrm{Th}$ is produced by dissolution of lithogenic material. There is no in situ production $(P=0)$ so that $\sigma_{\infty}=0$. It is assumed that all ${ }^{232} \mathrm{Th}$ dissolution (eolian and riverine sources) occurs in the surface waters, so that $\Phi_{i} \neq 0$ and $\Phi_{m} \neq 0$. With these conditions the profiles are given by:

$$
\begin{aligned}
& C_{d}^{i}=\left(\frac{\left(1+K_{m}\right) \Phi_{m}}{K_{m} S_{m}}-\frac{\left(1+K_{i}\right) \Phi_{i}}{K_{i} S_{i}}\right) \frac{F}{S_{i} V_{i} K_{i}} \\
& \times z_{0} \times\left(1-e^{-\left(\frac{z}{z_{0}}\right)}\right)+\frac{\Phi_{i}}{K_{i} S_{i}} \\
& C_{d}^{m}=\left(\frac{\left(1+K_{i}\right) \Phi_{i}}{K_{i} S_{i}}-\frac{\left(1+K_{m}\right) \Phi_{m}}{K_{m} S_{m}}\right) \frac{F}{S_{m} V_{m} K_{m}} \\
& \times z_{0} \times\left(1-e^{-\left(\frac{z}{z_{0}}\right)}\right)+\frac{\Phi_{m}}{K_{m} S_{m}}
\end{aligned}
$$




\section{Appendix B}

\section{Particular cases for in situ produced nuclides}

\section{B1 Identical scavenging conditions for the margin and the ocean interior}

When $K_{m}=K_{i}=K$ and $S_{m}=S_{i}=S$, Eqs. (A23) and (A24) become:

$\frac{c}{b}=\frac{P}{S K}$

$\sigma_{\infty}=(1+K) \frac{P}{S K}$

So that Eq. (26a) and (26b) become:

$C_{d}^{i}=C_{d}^{m}=\frac{P}{S K} \times z=\frac{\sigma_{\infty}}{1+K} \times z$

If the scavenging conditions are identical for the margin and the ocean interior, the net effect of advection can be neglected and ${ }^{230} \mathrm{Th}$ has a linear profile over the whole basin.

\section{B2 Close to the surface or if the residence time of the water is very long}

Close to the surface or if the residence time of the water is very long: $z / z_{0} \ll 1$

Then

$e^{-\left(z / z_{0}\right)} \approx 1-\frac{z}{z_{0}}$

Substituting Eq. (B4) in (A26a)

$C_{d}^{i} \approx \frac{\sigma_{\infty}}{\left(1+K_{i}\right)} \times z+\left(\frac{P}{S_{i} K_{i}}-\frac{\sigma_{\infty}}{\left(1+K_{i}\right)}\right) \times z_{0} \times\left(\frac{z}{z_{0}}\right)$

So that

$C_{d}^{i} \approx \frac{P}{S_{i} K_{i}} \times z$

and similarly for Eq. (B4) in (A26b)

$C_{d}^{m} \approx \frac{P}{S_{m} K_{m}} \times z$

Close to the surface $(z \rightarrow 0)$ or if the residence time of the water is very long in both margin and the open ocean $\left(z_{0} \rightarrow+\infty\right)$, the effect of lateral transport is negligible and the profiles are identical to those obtained without advection. At the sea surface $(z=0), C_{d}^{i}=C_{m}^{i}=0$, so that there is no horizontal concentration gradient and the effect of lateral transport is null. In contrast, at the sea surface, the vertical concentration gradient is not equal to zero so that the vertical transport entirely balances the in situ production.

As a consequence, it may be safe to determine the settling speed of marine particles with ${ }^{230} \mathrm{Th}$ data collected in the upper part of the water column rather than with the deep water data that are more affected by boundary scavenging.

\section{B3 At great depth or with a short water residence time in one of the reservoir}

When $z \rightarrow+\infty$ (great depth) or $z_{0} \rightarrow 0$ (short water residence time in at least one of the reservoir), then $z \gg z_{0}$

In this case:

$e^{-\left(\frac{z}{z_{0}}\right)} \approx 0$

Introducing Eq. (B7) in (A26a) and (A26b) yields:

$$
\begin{aligned}
& C_{t}^{i} \approx \sigma_{\infty} \times z+\left(\left(1+K_{i}\right) \frac{P}{S_{i} K_{i}}-\sigma_{\infty}\right) \times z_{0} \\
& C_{t}^{m} \approx \sigma_{\infty} \times z+\left(\left(1+K_{m}\right) \frac{P}{S_{m} K_{m}}-\sigma_{\infty}\right) \times z_{0}
\end{aligned}
$$

These equations represent straight lines with identical slopes but and a constant concentration offset between them. The concentration difference at a given depth is:

$C_{t}^{i}-C_{t}^{m} \approx\left(\left(1+K_{i}\right) \frac{P}{S_{i} K_{i}}-\left(1+K_{m}\right) \frac{P}{S_{m} K_{m}}\right) \times z_{0}$

So that:

$\frac{C_{t}^{i}-C_{t}^{m}}{P} \approx\left(\frac{1+K_{i}}{S_{i} K_{i}}-\frac{1+K_{m}}{S_{m} K_{m}}\right) \times z_{0}$

If the scavenging rate and the settling speed are much greater in the ocean margin $\left(S_{m} K_{m} \ll S_{i} K_{i}\right)$, Eq. (B10) and (A21) become:

$$
\begin{aligned}
& \frac{C_{t}^{i}-C_{t}^{m}}{P} \approx \frac{1+K_{i}}{S_{i} K_{i}} \times z_{0} \\
& z_{0} \approx\left(\frac{F}{V_{i}} \frac{\left(1+K_{i}\right)}{S_{i} K_{i}}\right)^{-1}
\end{aligned}
$$

So that

$$
\frac{C_{t}^{i}-C_{t}^{m}}{P} \approx \frac{\left(1+K_{i}\right)}{S_{i} K_{i}} \times z_{0} \approx \frac{V_{i}}{F}=\tau_{i}
$$

$\frac{C_{t}^{i}-C_{t}^{m}}{P}$ is the time required to generate this concentration difference by in situ radioactive production assuming that there is no scavenging, i.e., approximately the time spent by the water mass in the open ocean since it left the ocean margin $\left(\tau_{i}\right)$. In fact, it is lower than $\tau_{i}$, because scavenging in the open ocean removes part of the nuclides produced during $\tau_{i}$.

Ultimately, as $z$ increases, the second term of the right hand-side of Eq. (B8a) and (B8b) becomes negligible, so that these equations become

$C_{t}^{i} \approx \sigma_{\infty} \times z$

and

$C_{t}^{m} \approx \sigma_{\infty} \times z$ 
It means that when the water residence time is small compared to scavenging time in one of the reservoir at least, the total ${ }^{230} \mathrm{Th}$ concentration is homogenized by lateral mixing.

Theoretically, the $C_{t}^{i}$ and $C_{t}^{m}$ are never perfectly equal at a given depth as indicated by Eq. (B10), but as depth increases the difference of concentration $C_{t}^{i}-C_{t}^{m}$ becomes small compared to the concentration themselves.

\section{B4 Comparison of the boundary scavenging profile model with Venchiarutti et al. (2008)}

If $V_{i} \gg V_{m}$ and $\frac{S_{i} V_{i} K_{i}}{\left(1+K_{i}\right)} \gg \frac{S_{m} K_{m} V_{m}}{\left(1+K_{m}\right)}$ (the inner ocean is much larger than the ocean margin and despite a lower scavenging rate in the inner ocean most of the ${ }^{230} \mathrm{Th}$ is scavenged in the inner ocean because its volume is so large compared to the margin).

Equation (A24) can be approximated by:

$\sigma_{\infty} \approx\left(1+K_{i}\right) \frac{P}{S_{i} K_{i}}$

and Eq. (A22) can be approximated by:

$z_{0} \approx \frac{V_{m}}{F} \frac{S_{m} K_{m}}{\left(1+K_{m}\right)}$

So that Eq. (A26a) and (A26b) become:

$C_{d}^{i}=\frac{P}{S_{i} K_{i}} \times z$

(the profile increases linearly in the open ocean)

$$
\begin{aligned}
C_{d}^{m}= & \frac{\left(1+K_{i}\right)}{\left(1+K_{m}\right)} \frac{P}{S_{i} K_{i}} \times z+\left(\frac{P}{S_{m} K_{m}}-\frac{\left(1+K_{i}\right)}{\left(1+K_{m}\right)} \frac{P}{S_{i} K_{i}}\right) \\
& \times z_{0} \times\left(1-e^{-\left(\frac{z}{z_{0}}\right)}\right)
\end{aligned}
$$

Using Eq. (B14), Eq. (B16b) can be arranged as:

$$
\begin{aligned}
C_{d}^{m}= & \left(\frac{P}{S_{m} K_{m}}\right) \times z_{0} \times\left(1-e^{-\left(\frac{z}{z_{0}}\right)}\right) \\
& +\left(\frac{\sigma_{\infty}}{\left(1+K_{m}\right)}\right) \times z_{0} \times\left(\frac{z}{z_{0}}-1+e^{-\left(\frac{z}{z_{0}}\right)}\right)
\end{aligned}
$$

This expression is equivalent to Eq. (13) obtained in Venchiarutti et al. (2008).
Acknowledgements. The author thanks C. Jeandel for her encouragements to achieve this project. The comments of C. Jeandel, C. Venchiarutti and J.-C. Dutay significantly improved the manuscript. M. Siddall has provided interesting discussions concerning particle flux modelling. M. Rutgers van der Loeff and R. Anderson are acknowledged for their thorough reviews. This is LSCE contribution 4019 .

Edited by: C. Heinze

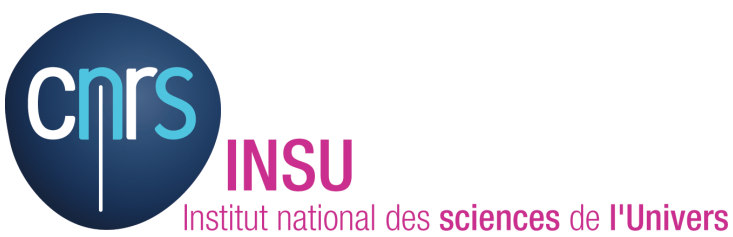

The publication of this article is financed by CNRS-INSU.

\section{References}

Anderson, L. G., Jones, E. P., and Rudels, B.: Ventilation of the Arctic Ocean estimated by a plume entrainment model constrained by CFCs, J. Geophys. Res., 104, 13 423-13 429, 1999.

Anderson, R. F., Bacon, M. P., and Brewer, P. G.: Removal of ${ }^{231} \mathrm{~Pa}$ and ${ }^{230}$ Th at ocean margins, Earth Planet. Sc. Lett., 66, 73-90, 1983.

Arraes-Mescoff, R., Coppola, L., Roy-Barman, M., Souhaut, M., Tachikawa, K., Jeandel, C., Sempéré, R., and Yoro, C.: The behavior of $\mathrm{Al}, \mathrm{Mn}, \mathrm{Ba}, \mathrm{Sr}, \mathrm{REE}$ and $\mathrm{Th}$ isotopes during in vitro bacterial degradation of large marine particles, Mar. Chem., 73, 1-19, 2001.

Arsouze, T., Dutay, J.-C., Lacan, F., and Jeandel, C.: Modelling the neodymium isotopic composition with a global ocean general circulation model, Chem. Geol., 239, 165-177, 2007.

Bacon, M. P.: ${ }^{210} \mathrm{~Pb}$ and ${ }^{210} \mathrm{Po}$ results from F. S. Meteor cruise 32 in the North Atlantic, Meteor. Forschungs-Ergebnisse, 19, 24 36, 1977.

Bacon, M. P.: Tracers of chemical scavenging in the ocean: boundary effects and large scale chemical fractionation, Philos. T. Roy. Soc. A, 325, 147-160, 1988.

Bacon, M. P. and Anderson, R. F.: Distribution of thorium isotopes between dissolved and particulate forms in the Deep-Sea, J. Geophys. Res., 87, 2045-2056, 1982.

Bacon, M. P., Huh, C.-A., and Moore, R. M.: Vertical profiles of some natural radionuclides over the Alpha Ridge, Arctic Ocean, Earth Planet. Sc. Lett., 95, 15-22, 1989.

Bacon, M. P., Huh, C.-H., Fleer, A. P., and Deuser, W. G.: Seasonality in the flux of natural radionuclides and plutonium in the deep Sargasso Sea, Deep-Sea Res., 32, 273-286, 1985.

Boyle, E. A., Berquist, B. A., Kayser, R. A., and Mahowald, N.: Iron, manganese, and lead at Hawaii Ocean Time-series station ALOHA: Temporal variability and an intermediate water hydrothermal plume, Geochim. Cosmochim. Ac., 69, 933-952, 2005.

Broecker, W.: Excess sediment ${ }^{230} \mathrm{Th}$ : Transport along the sea floo or enhanced water column scavenging?, Global Biogeochem. Cy., 22, GB1006, doi:10.1029/2007GB003057, 2008. 
Carmack, E. C., Aagaard, K., Swift, J. H., Macdonald, R. W., McLaughlin, F. A., Jones, E. P., Perkin, R. G., Smith, J. N., Ellis, K. M., and Kilius, L.: Changes in temperature and tracer distributions within the Arctic Ocean: Results from the 1994 Arctic Ocean Section, Deep-Sea Res. Pt. II, 44, 1487-1502, 1997.

Chase, Z., Anderson, R. F., Fleisher, M. Q., and Kubik, P. W.: The influence of particle composition and particle flux on scavenging of Th, $\mathrm{Pa}$ and $\mathrm{Be}$ in the ocean, Earth Planet. Sc. Lett., 204, 215229, 2002.

Cochran, J. K., Hirschberg, D. J., Livingston, H. D., Buesseler, K. O., and Key, R. M.: Natural and anthropogenic radionuclide distributions in the Nansen Basin, Arctic Ocean: scavenging rates and circulation timescales, Deep-Sea Res. Pt. II, 42, 1495-1517, 1995.

Coppola, L., Roy-Barman, M., Mulsow, S., Povinec, P., and Jeandel, C.: Thorium isotopes as tracers of particles dynamics and deep water circulation in the Indian sector of the Southern Ocean (ANTARES IV), Mar. Chem., 100, 299-313, 2006.

Duce, R. A., Liss, P. S., Merrill, J. T., Atlas, E. L., Buat-Ménard, P., Hicks, B. B., Miller, J. M., Prospero, J. M., Arimoto, R., Church, T. M., Ellis, W., Galloway, J. N., Hansen, L., Jickells, T. D., Knap, A. H., Reinhardt, K. H., Schneider, B., Soudine, A., Tokos, J. J., Tsunogai, S., Wollast, R., and Zhou, M.: The atmospheric input of trace species to the world ocean., Global Biogeochem. Cy., 5, 193-259, 1991.

Dutay, J.-C., Lacan, F., Roy-Barman, M., and Bopp, L.: Study of the influence of the particles' size and type on the simulation of ${ }^{231} \mathrm{~Pa}$ and ${ }^{230} \mathrm{Th}$ with a global coupled biogeochemical- ocean general circulation model: a first approach, Geochem. Geophy. Geosy., 10, Q01011, doi:10.1029/2008GC002291, 2009.

Edmonds, H. N., Moran, S. B., Cheng, H., and Edwards, R. L.: ${ }^{230} \mathrm{Th}$ and ${ }^{231} \mathrm{~Pa}$ in the Arctic Ocean: implications for particle fluxes and basin-scale $\mathrm{Th} / \mathrm{Pa}$ fractionation, Earth Planet. Sc. Lett., 227, 155-167, 2004.

Edmonds, H. N., Moran, S. B., Hoff, J. A., Smith, J. N., and Edwards, R. L.: Protactinium-231 and Thorium-230 abundances and high scavenging rates in the Western Arctic Ocean, Science, 280, 405-407, 1998.

Fine R. A., Maillet K. A., Sullivan K. F., and Willey D.: Circulation and ventilation flux of the Pacific Ocean, J. Geophys. Res., 106, 22 159-22 178, 2001.

Henderson, G. M., Heinze, C., Anderson, R. F., and Winguth, A. M. E.: Global distribution of the ${ }^{230}$ Th flux to ocean sediments constrained by GCM modelling, Deep-Sea Res. Pt. I, 46, 18611893, 1999.

Hoffmann, S. and McManus, J.: Is there a ${ }^{230}$ Th deficit in Arctic sediments?, Earth Planet. Sc. Lett., 258, 516-527, 2007.

Huh, C.-A., Pisias, N. G., Kelley, J. M., Maiti, T. C., and Grantz, A.: Natural radionuclides and plutonium in sediments from the western Arctic Ocean: sedimentation rates and pathways of radionuclides, Deep-Sea Res. Pt. II, 44, 1725-1743, 1997.

Jakobsson, M.: Hypsometry and volume of the Arctic Ocean and its constituent seas, Geochem. Geophy. Geosy., 3, 1028, doi10.1029/2001GC000302, 2002.

Jeandel, C., Arsouze, T., Lacan, F., Téchiné, P., and Dutay, J.-C.: Isotopic $\mathrm{Nd}$ compositions and concentrations of the lithogenic inputs into the ocean: A compilation, with an emphasis on the margins, Chem. Geol., 239, 156-164, 2007.

Lacan, F. and Jeandel, C.: Neodymium isotopes as a new tool for quantifying exchange fluxes at the continent-ocean interface, Earth Planet. Sc. Lett., 232, 245-257, 2005.

Ledwell, J. R., Montgomery, E. T., Polzin, K. L., St Laurant, L. C., Schmitt, R. W., and Toole, J. M.: Evidence for enhanced mixing over rough topography in the abyssal ocean, Nature, 403, 179$82,2000$.

Ledwell, J. R., Watson, A. J., and Laws, C. S.: Mixing of a tracer in the pycnocline, J. Geophys. Res., 108, 21 499-21 529, 1998.

Marchal, O., François, R., and Scholten, I.: Contribution of ${ }^{230} \mathrm{Th}$ measurements to the estimation of the abyssal circulation, DeepSea Res. Pt. I, 54, 557-585, 2007.

Matsumoto, K.: Radiocarbon-based circulation age of the world oceans, J. Geophys. Res., 112, C09004, doi:10.1029/2007JC004095, 2007.

Milliman, J. D. and Meade, R. H.: World-wide delivery of river sediment to the oceans, J. Geol., 91, 1-21, 1983.

Moran, S. B., Shen, C.-C., Edmonds, H. N., Weinstein, S. E., Smith, J. N., and Edwards, R. L.: Dissolved and particulate ${ }^{231} \mathrm{~Pa}$ and ${ }^{230} \mathrm{Th}$ in the Atlantic Ocean: constraints on intermediate/deep water age, boundary scavenging, and ${ }^{231} \mathrm{~Pa} /{ }^{230} \mathrm{Th}$ fractionation, Earth Planet. Sc. Lett., 203, 999-1014, 2002.

Moran, S. B., Shen, C.-C., Edwards, R. L., Edmonds, H. N., Scholten, J. C., Smith, J. N., and Ku, T.-L.: ${ }^{231} \mathrm{~Pa}$ and ${ }^{230} \mathrm{Th}$ in surface sediments of the Arctic Ocean: Implications for ${ }^{231} \mathrm{~Pa} /{ }^{230} \mathrm{Th}$ fractionation, boundary scavenging and advective export, Earth Planet. Sc. Lett., 234, 235-248, 2005.

Munk, W.: Abyssal recipes, Deep-Sea Res., 13, 207-30, 1966.

Nozaki, Y., Horibe, Y., and Tsubota, H.: The water column distribution of thorium isotopes in the western North Pacific, Earth Planet. Sc. Lett., 54, 203-216, 1981.

Nozaki, Y. and Nakanishi, T.: ${ }^{231} \mathrm{~Pa}$ and ${ }^{230} \mathrm{Th}$ in the open ocean water column, Deep-Sea Res., 32, 1209-1220, 1985.

Nozaki, Y., Yamada, M., Nakanishi, T., Nagaya, Y., Nakamura, K., Shitashima, K., and Tsbota, H.: The distribution of radionuclides and some trace metals in the water columns of the Japan and Bonin trenches, Oceanol. Acta, 21, 469-484, 1995.

Nozaki, Y., and Yang, H.-S.: Th and Pa isotopes in the waters of the western margin of the Pacific near Japan: Evidence for release of ${ }^{228} \mathrm{Ra}$ and ${ }^{227} \mathrm{Ac}$ from slope sediments, Journal of Oceanographic Society of Japan, 43, 217-227, 1987.

Nozaki, Y., Yang, H.-S., and Yamada, M.: Scavenging of thorium in the ocean, J. Geophys. Res., 92, 772-778, 1987.

Owens, W. B. and Warren, B. A.: Deep circulation in the northwest corner of the Pacific Ocean, Deep-Sea Res. Pt. I, 48, 959-993, 2001.

Reid, J. L.: On the total geostrophic circulation of the Pacific Ocean: flow patterns, tracers, and transports, Prog. Oceanogr., 39, 263 352, 1997.

Roy-Barman, M., Chen, J. H., and Wasserburg, G. J.: ${ }^{230}{ }^{T h}-{ }^{232} \mathrm{Th}$ systematics in the Central Pacific Ocean: the sources and the fates of thorium, Earth Planet. Sc. Lett., 139, 351-363, 1996.

Roy-Barman, M., Coppola, L., and Souhaut, M.: Thorium isotopes in the Western Mediterranean Sea: an insight into the marine particle dynamics, Earth Planet. Sc. Lett., 196, 161-174, 2002.

Roy-Barman, M., Jeandel, C., Souhaut, M., Rutgers van der Loeff, M., Voege, I., Leblond, N., and Freydier, R.: The influence of particle composition on thorium scavenging in the NE Atlantic ocean (POMME experiment), Earth Planet. Sc. Lett., 240, 681693, 2005. 
Roy-Barman, M., Lemaître, C., Ayrault, S., Jeandel, C., Souhaut, M. and J.-C. Miquel: The influence of particle composition on Thorium scavenging in the Mediterranean Sea, Earth Planet. Sc. Lett., 286, 526-534, 2009.

Rudels, B., Jones, E. P., Anderson, L. G., and Kattner, G.: On the intermediate depth waters of the Arctic Ocean, in: The Polar Oceans and Their Role in Shaping the Global Environment, edited by: Johannessen, O. M., Muench, D., and Overland, J. E., Geophys. Monogr. Ser., AGU, Washington, D. C., 85, 33-46, 1994.

Rutgers van der Loeff, M. M. and Berger, G. W.: Scavenging of ${ }^{230} \mathrm{Th}$ and ${ }^{231} \mathrm{~Pa}$ near the Antarctic Polar Front in the South Atlantic, Deep-Sea Res., 40, 339-357, 1993.

Santschi, P. H., Murray, J. W., Baskaran, M., Benitez-Nelson, C. R., Guo, L. D., Hung, C.-C., Lamborg, C., Moran, S. B., Passow, U., and Roy-Barman, M.: Thorium speciation in seawater, Mar. Chem., 100, 250-268, 2006.

Sarmiento, J. L. and Rooth, C. G. H.: A comparison of vertical and isopycnal mixing models in the deep sea based on radon 222 measurements, J. Geophys. Res., 85, 1515-1518, 1980.

Sarmiento, J. L., Rooth, C. G. H., and Broecker, W. S.: Radium 228 as a Tracer of Basin Wide Processes in the Abyssal Ocean, J. Geophys. Res., 87 , 9694-9698, 1982.

Schlosser, P., Bonisch, G., Kromer, B., Loosli, H. H., Bohler, B., Bayer, R., Bonani, G., and Kolterman, K. P.: Mid-1980s distribution of tritium, 3He, $14 \mathrm{C}$ and 39Ar in the Greenland/Norwegian Seas and the Nansen Basin of the Arctic Ocean, Prog. Oceanogr., $35,1-28,1995$

Schlosser, P., Kromer, B., Ekwurzel, B., Bönisch, G., McNichol, A., Schneider, R., von Reden, K., Ostlund, H. G., and Swift, J. H.: The first trans-Arctic $14 \mathrm{C}$ section: comparison of the mean ages of the deep waters in the Eurasian and Canadian basins of the Arctic Ocean, Nucl. Instrum. Meth. B, 123, 431-437, 1997.

Scholten, J. C., Fietzke, J., Mangini, A., Garbe-Schönberg, C.-D., Eisenhauer, A., Schneider, R., and Stoffers, P.: Advection and scavenging: Effects on ${ }^{230} \mathrm{Th}$ and ${ }^{231} \mathrm{~Pa}$ distribution off Southwest Africa, Earth Planet. Sc. Lett., 271, 159-169, 2008.

Scholten, J. C., Rutgers van der Loeff, M. M., and Michel, A.: Distribution of ${ }^{230} \mathrm{Th}$ and ${ }^{231} \mathrm{~Pa}$ in the water column in relation to the ventilation of the deep Arctic basins, Deep-Sea Res. Pt. II, 42, 1519-1531, 1995.
Siddall, M., Anderson, R. F., Winckler, G., Henderson, G. M., Bradtmiller, L. I., McGee, D., Franzese, A., Stocker, T. F., and Müller, S. A.: Modeling the particle flux effect on distribution of 230Th in the equatorial Pacific, Paleoceanography, 23, PA2208, doi:10.1029/2007PA001556, 2008.

Siddall, M., Henderson, G. M., Edwards, N. R., Müller, S. A., Stocker, T. F., Joos, F., and Frank, M.: 231Pa/230Th fractionation by ocean transport, biogenic particle flux and particle type, Earth Planet. Sc. Lett., 237, 137-155., 2005.

Siddall, M., Stocker, T. F., Henderson, G. M., Joos, F., Frank, M., Edwards, N. R., Ritz, S., and Müller, S. A.: Modelling the relationship between ${ }^{231} \mathrm{~Pa} /{ }^{230} \mathrm{Th}$ distribution in North Atlantic sediment and Atlantic Meridional Overturning Circulation, Paleoceanography, 22, PA2214, doi:10.1029/2006PA001358, 2007.

Spencer, D. W., Bacon, M. P., and Brewer, P. G.: Models of the distribution of $210 \mathrm{~Pb}$ in a section across the north Equatorial Atlantic Ocean, J. Mar. Res., 39, 119-138, 1981.

Taguchi, K., Harada, K., and Tsunogai, S.: Particulate removal of ${ }^{230} \mathrm{Th}$ and ${ }^{231} \mathrm{~Pa}$ in the biologically productive northern North Pacific, Earth Planet. Sc. Lett., 93, 223-232, 1989.

Tanhua, T., Jones, E. P., Jeansson, E., Jutterström, S., Smethie, W. M., Wallace, D. W. R., and Anderson, L. G.: Ventilation of the Arctic Ocean: mean ages and inventories of anthropogenic $\mathrm{CO}_{2}$ and CFC-11, J. Geophys. Res., 114, C01002, doi:10.1029/2008JC0048682009, 2009.

Thorpe, S. A.: Recent developments in the study of ocean turbulence, Annu. Rev. Earth Pl. Sc., 32, 91-109, 2004.

Uematsu, M., Duce, R. A., and Prospero, J. M.: Deposition of atmospheric mineral particles in the North Pacific ocean, J. Atmos. Chem., 3, 123-138, 1985.

Venchiarutti, C., Jeandel, C., and Roy-Barman, M.: Particle dynamics in the wake of Kerguelen Island traced by thorium isotopes (Southern Ocean, KEOPS program), Deep-Sea Res. Pt. I, 55, 1343-1363, 2008.

Wallace, D. W. R. and Moore, R. M.: Vertical profiles of CC13F (F-11) and CC12F (F-12) in the central Arctic Ocean basin, J. Geophys. Res., 90, 1155-1166, 1985.

Yanagimoto, D. and Kawabe, M.: Deep-circulation flow at midlatitude in the western North Pacific, Deep-Sea Res. Pt. I, 54, 2067-2081, 2007. 